\title{
Avaliação do Balanço de Água na Bacia do Rio Madeira Simulado Pelo Modelo Regional Climático Eta e o Modelo Hidrológico de Grandes Bacias MGB
}

\author{
Leonardo Alves Vergasta $^{1}$ (D), Francis Wagner Silva Correia ${ }^{2}$, Sin Chan Chou ${ }^{3}$, Paulo Nobre ${ }^{3}$, \\ André de Arruda Lyra $^{3}$, Weslley de Brito Gomes ${ }^{1}$, Vinicius Capistrano ${ }^{2}$, José Augusto P. Veiga ${ }^{1}$ \\ ${ }^{1}$ Programa de Pós-Graduação em Clima e Ambiente, Instituto Nacional de Pesquisas da \\ Amazônia, Manaus, AM, Brasil. \\ ${ }^{2}$ Departamento de Meteorologia, Universidade do Estado do Amazonas, Manaus, AM, Brasil. \\ ${ }^{3}$ Centro de Previsão de Tempo e Estudos Climáticos, Instituto Nacional de Pesquisas Espaciais, \\ Cachoeira Paulista, SP, Brasil.
}

Recebido em: 17 de Abril de 2020 - Aceito em: 25 de Agosto de 2020

\begin{abstract}
Resumo
Simulações climáticas para o clima presente (1960-2005) utilizando o Modelo Climático Regional Eta e o Modelo Hidrológico de Grandes Bacias (MGB), forçado com o Brazilian Earth System Model Ocean-Atmosphere (BESM-AO 2.5) foram realizadas. O objetivo deste trabalho é avaliar o desempenho do Modelo Regional Eta e o Modelo Hidrológico de Grandes Bacias (MGB) na representação dos componentes do balanço de água (precipitação, evapotranspiração, convergência de umidade, vazão, cota e área de inundação) sobre a bacia do rio Madeira. A característica de sumidouro de umidade $(\mathrm{P}>\mathrm{E})$ foi simulada pelo modelo regional. Entretanto, o modelo subestimou a precipitação (33\%), a evapotranspiração (12\%) e a convergência de umidade (6\%). O MGB-IPH conseguiu representar o ciclo anual das vazões, níveis do rio (cota) e área de inundação. Também conseguiu reproduzir a translação e amplitude das ondas de cheia, e o atraso de 3 meses entre os máximos da área de inundação e a precipitação sobre a bacia do Madeira. O MGB-IPH mostrou-se uma ferramenta útil para estudos de variabilidade climática, mudanças no clima e no uso da terra, e também para sistemas operacionais de previsão hidrológica na bacia Amazônica.
\end{abstract}

Palavras-chave: Bacia do rio Madeira, balanço de água, vazão, níveis d'água, área de inundação.

\section{Assessment of the Water Budget in Madeira River Basin Simulated by the Eta Regional Climate And MGB Large-Scale Hydrological Models}

\begin{abstract}
Downscaling climate simulation for present climate (1960-2005) based on the Eta Regional Climate Model and MGB Large-scale Hydrological Model, forced by Brazilian Model of the Terrestrial System (BESM-AO 2.5), was carried out. The objective of this work is assessment the performance of the Eta regional model and MGB-IPH in the representation of the components of the water budget in Madeira River basin. The moisture sink characteristic $(\mathrm{P}>\mathrm{E})$ was simulated by the regional model. In the terrestrial branch, the MGB-IPH hydrological model was able to represent the annual cycle of discharge, water level and floodplain inundation. The performance of the hydrological model and the regional model was satisfactory in the simulation of the seasonal dynamics of hydrological processes and water budget in Madeira river basin, indicating that the hydrological model is a useful tool for studies of climatic variability, changes in climate and land use and for hydrological forecasting operational systems in the Amazon basin.
\end{abstract}

Keywords: Madeira River Basin, water balance, flow rate, water levels, flood area.

Autor de correspondência: Leonardo Alves Vergasta, lav.dcl18@.ea.edu.br. 


\section{Introdução}

A Amazônia é a maior bacia hidrográfica do mundo, abrangendo uma área de aproximadamente 7 milhões $\mathrm{km}^{2}$, abrangendo vários países da América do Sul: Brasil, Peru, Equador, Bolívia, Colômbia, Venezuela e Guiana. A floresta amazônica cobre uma área de 5,3 milhões $\mathrm{km}^{2}$, o que representa $40 \%$ das áreas de florestas tropicais do planeta (Marengo et al., 2018). A sua área de drenagem apresenta uma área com cerca de um terço do continente sul-americano e uma vazão variando de $210.000 \mathrm{~m}^{3} \mathrm{~s}^{-1}$ a $220.000 \mathrm{~m}^{3} \mathrm{~s}^{-1}$, contribuindo com aproximadamente $15 \%$ do volume de água doce afluente aos oceanos (Marengo e Espinoza, 2016; Nobre et al., 2016; Chaudhari et al., 2019).

A bacia do rio Madeira é o principal tributário da porção sul da Bacia Amazônica representando $23 \%$ do total da bacia e estendendo-se por três países: Bolívia, Brasil e Peru. Com uma extensão de $3.250 \mathrm{~km}$, a bacia do rio Madeira desempenha papel fundamental no desenvolvimento social e econômico da região através da navegação (transporte de passageiros e cargas), irrigação de cultivos agrícolas e a produção de energia elétrica por meio das usinas de Jirau e Santo Antônio (ANTAQ, 2011).

Entretanto, as mudanças e variabilidade no clima têm afetado a dinâmica fluvial dos principais rios da Bacia Amazônica, principalmente a do rio Madeira (Espinoza et al., 2014; Júnior et al., 2015, Marengo e Espinoza, 2016). Nos últimos anos o aumento na frequência e intensidade dos eventos de secas e enchentes produziram prejuízos e danos no meio-ambiente, nos recursos hídricos, na economia e nas cidades e comunidades que vivem às margens dos rios, principalmente as populações vulneráveis na Amazônia (Gloor et al., 2013; Espinoza et al., 2013; Espinoza et al., 2014; Doughty et al., 2015; Marengo e Espinoza, 2016). Nos últimos 15 (quinze) anos ocorreram duas grandes secas (2005 e 2010) e duas grandes enchentes (2009 e 2012) na região (Espinoza et al., 2014). Recentemente o sudoeste da Amazônia, e principalmente a bacia do rio Madeira, sofreram com enchentes e chuvas históricas no verão austral 2013-14, trazendo transtornos e prejuízos para população, tais como: famílias desabrigadas, interdição de estradas, isolamentos de comunidades, prejuízos na agricultura e transporte, desabastecimento nos municípios e doenças transmitidas por contaminação da água (Marengo e Espinoza, 2016).

Um melhor entendimento do clima e suas variabilidades na bacia do rio Madeira são limitados pela escassez medições, que dificulta estudos de variabilidade dos componentes do balanço de água na região. Neste sentido, os Modelos de Sistema Terrestre (MST) e Modelos Regionais (MR) - área limitada - apresentam-se como ferramentas úteis para avaliar as características do balanço de água e suas variabilidades; assim como, projeções do clima decorrente dos efeitos antropogênicos (Goddard et al., 2001). Devido a sua resolução, os modelos regionais conseguem representar com mais detalhes os processos físicos (convecção, microfísica de nuvens, superfície, radiação e processos turbulentos) e as forçantes de mesoescala (Chou et al., 2011), permitindo maior detalhamento espacial e temporal das variáveis do sistema climático, mostrando-se útil para estudos do balanço de água em escala regional. Entretanto, devido à existência de erros sistemáticos se faz necessário a avaliação do desempenho desses modelos para que se possa atribuir algum grau de confiança nas simulações climáticas. Desta forma, este trabalho tem por objetivo realizar um estudo de modelagem numérica a fim de avaliar o desempenho do Modelo Regional Eta e do Modelo Hidrológico de Grandes Bacias (MGB), forçado com o Brazilian Earth System Model Ocean-Atmosphere (BESM-AO 2.5), na representação dos componentes do balanço de água (atmosférico e terrestre) sobre a bacia do rio Madeira para o clima presente.

\section{Materiais e Métodos}

Para avaliação do desempenho do ramo atmosférico do balanço de água na bacia do rio Madeira realizou-se uma simulação numérica para o clima presente (19602005) utilizando o Modelo Regional Eta (Chou et al., 2014b), forçado com as condições iniciais e de contorno provenientes do Brazilian Earth System Model OceanAtmosphere versão 2.5 (BESM-OA 2.5) por meio do processo de downscaling dinâmico, porém para este estudo avaliou-se de 1979 a 2005. Para avaliação do desempenho do ramo terrestre do balanço de água (vazão, nível (cota) e área de inundação) o Modelo Hidrológico de Grandes Bacias - Instituto de Pesquisas Hidráulicas (MGB-IPH) foi forçado com as condições climáticas do Modelo Regional Eta.

\section{1. Área de estudo}

A bacia do rio Madeira (Fig. 1) caracteriza-se pelo clima quente e úmido (clima equatorial), com temperatura média anual variando entre $24{ }^{\circ} \mathrm{C}$ e $26{ }^{\circ} \mathrm{C}$ na planície Amazônica (Ribeiro Neto et al., 2008). A bacia possui uma área de drenagem de aproximadamente 1.4 milhão de $\mathrm{km}^{2}$, da qual $51 \%$ pertencem à Bolívia, $42 \%$ ao Brasil e $7 \%$ ao Peru (Ribeiro Neto et al., 2008). A vazão média é de aproximadamente $31.704 \mathrm{~m}^{3} \mathrm{~s}^{-1}$, que corresponde a $15 \%$ da descarga média do Rio Amazonas na sua foz (Júnior et al., 2015). A precipitação média na bacia é da ordem de $1834 \mathrm{~mm}_{\text {ano }}{ }^{-1}$ (Molinier et al., 1996), com uma forte variabilidade espacial variando de $255 \mathrm{~mm} \mathrm{ano}^{-1}$ na estação de Caracato $(2650 \mathrm{~m}$ ) nos Andes boliviano a mais de $3000 \mathrm{~mm}$ ano $^{-1}$ em estações localizadas a menos que $1500 \mathrm{~m}$ de altitude (Espinoza Villar et al., 2009). O rio Madeira responde cerca de 35\% $\left(240 \times 106 \mathrm{t} \mathrm{ano}^{-1}\right)$ de toda a carga de sedimentos transportada pelo rio Amazo- 


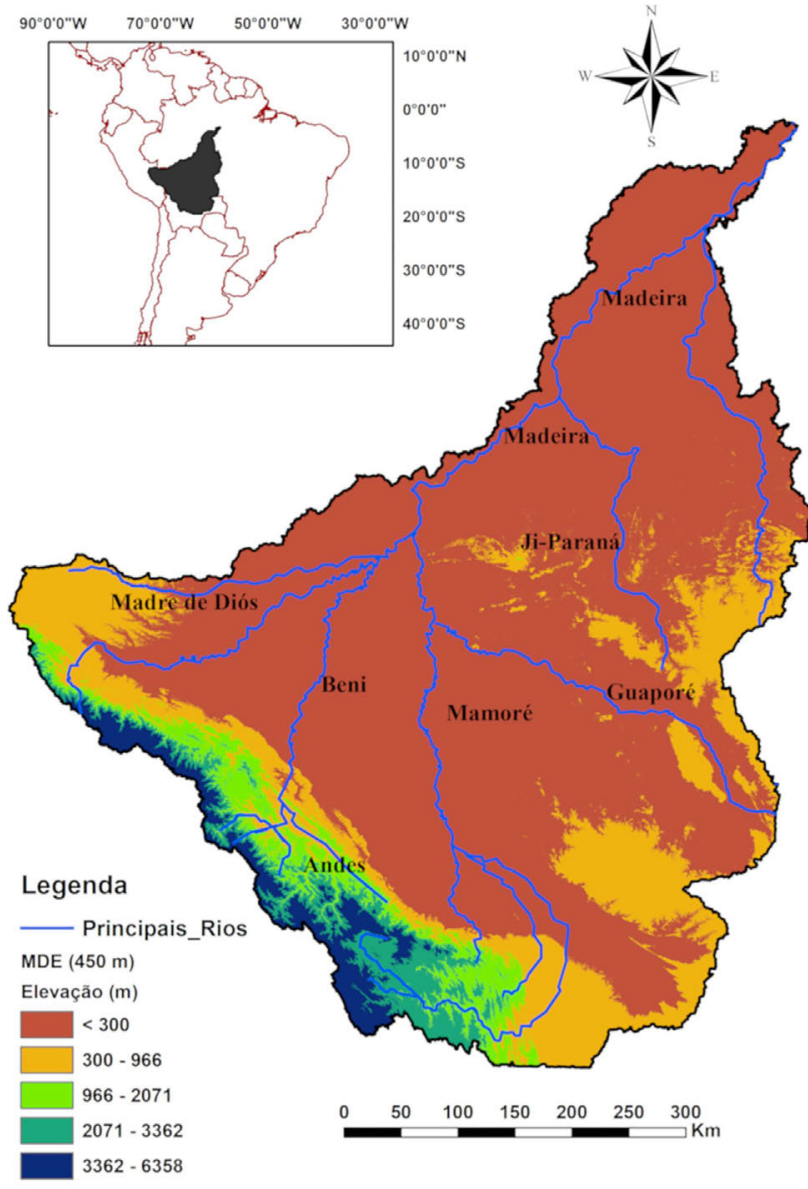

Figura 1 - Localização hidrográfica e relevo da Bacia do Rio Madeira. Fonte: SRTM - Universidade de Bristol. Disponível em: http://www.bristol.ac.uk.

nas ao Oceano Atlântico, dos quais a sua maior parte vem das áreas Andinas da bacia (Guyot, 1993).

\subsection{Dados}

Para avaliação do desempenho do modelo regional Eta-BESM-OA na representação do ramo atmosférico do balanço de água (precipitação, evapotranspiração, convergência de umidade e escoamento total) na bacia do rio Madeira foi utilizado as reanálises do Era-Interim (European Centre for Medium-Range Weather Forecasts ECMWF), com resolução espacial de $1.0^{\circ} \times 1.0^{\circ}$ (Dee et al., 2011). A avaliação foi baseada nos campos médios sazonais para o Verão: Dezembro-Janeiro- Fevereiro (DJF) e Inverno: Junho-Julho-Agosto (JJA). As métricas estatísticas utilizadas para validação foram o viés (bias) e a raiz quadrada do erro médio quadrático (RMSE). A avaliação foi realizada para o período de 1979 a 2005. O escoamento total (runoff) foi estimado a partir da diferença entre precipitação e a evapotranspiração, ambas provenientes das reanálises do Era-Interim.
Para a avaliação do desempenho do modelo MGBIPH utilizaram-se as medições de vazão das estações fluviométricas da Agência Nacional de Águas (ANA) disponíveis no sítio de Sistema de Informações Hidrológicas para o período de 1995 e 2005.

Para avaliar o desempenho dos níveis d'água (cota) foram utilizadas medidas diárias de nível d'água do Serviço Geológico do Brasil (CPRM) para o período de 1995 a 2005. As métricas estatísticas utilizadas para a calibração e validação da vazão foram, os coeficientes NashSutcliffe (ENS), Nash-Sutcliffe para os logaritmos das vazões (ENSlog) e o erro do volume $(\Delta \mathrm{V}$ em \%) (Nash, 1970).

Para avaliar o desempenho dos níveis d'água foram utilizadas as seguintes métricas estatísticas: coeficiente de correlação, índice de eficiência de Nash Sutcliffe (ENS), erro absoluto de amplitude (Viés) A1 (m) e erro relativo da amplitude A2 (Viés \%). Para a avaliação da área de inundação, o MGB-IPH foi forçado com dados de precipitação provenientes das reanalises do Era-Interim e do modelo regional Eta-BESM-OA, utilizando o erro relativo (Viés) como critério de avaliação. As estações utilizadas nesse estudo são apresentadas na Tabela 1 e Fig. 2.

\subsection{Descrição dos modelos e estratégia de integração numérica}

Para a simulação numérica do clima presente foi utilizado o Modelo Regional Eta (Chou et al., 2014a; Chou et al., 2014b), forçado com modelo de circulação geral Brazilian Earth System Model Ocean-Atmosphere versão 2.5 (BESM-OA 2.5), ambos do Centro de Previsão do Tempo e Estudo Climáticos do Instituto Nacional de Pesquisas Espaciais (CPTEC/INPE). Daqui por diante a simulação de downscaling será referida por Eta-BESM-OA. O Brazilian Earth System Model Ocean-Atmosphere versão 2.5 BESM-OA 2.5 (Nobre et al., 2013) é um modelo espectral Euleriano com truncamento T62 e 28 níveis na atmosfera. Este modelo é constituído pelo modelo de circulação geral da atmosfera (AGCM) do Centro de Previsão de Tempo e Estudos Climáticos - CPTEC/INPE (Figueroa et al., 2016) acoplado ao modelo de circulação geral oceânico

Tabela 1 - Estações fluviométricas da Agência Nacional de Águas (ANA).

\begin{tabular}{cccccc}
\hline $\mathrm{N}^{\circ}$ & Código & Nome & $\mathrm{A}\left(\mathrm{km}^{2}\right)$ & Lat & Lon \\
\hline 1 & 15250000 & Guajará-Mirim & 589.497 & -10.79342 & -65.34815 \\
2 & 15400000 & Porto Velho & 954.285 & -8.74824 & -63.91860 \\
3 & 15430000 & Ariquemes & 7.795 & -9.92719 & -63.06009 \\
4 & 15580000 & Tabajara & 60.212 & -8.93161 & -62.05573 \\
5 & 15630000 & Humaitá & 10.66240 & -7.50205 & -63.01475 \\
6 & 15700000 & Manicoré & 11.57516 & -5.81473 & -61.30596 \\
7 & 15750000 & Humboldt & 15.213 & -10.16878 & -59.46468 \\
\hline
\end{tabular}

Fonte: Agência Nacional de Águas (ANA) 


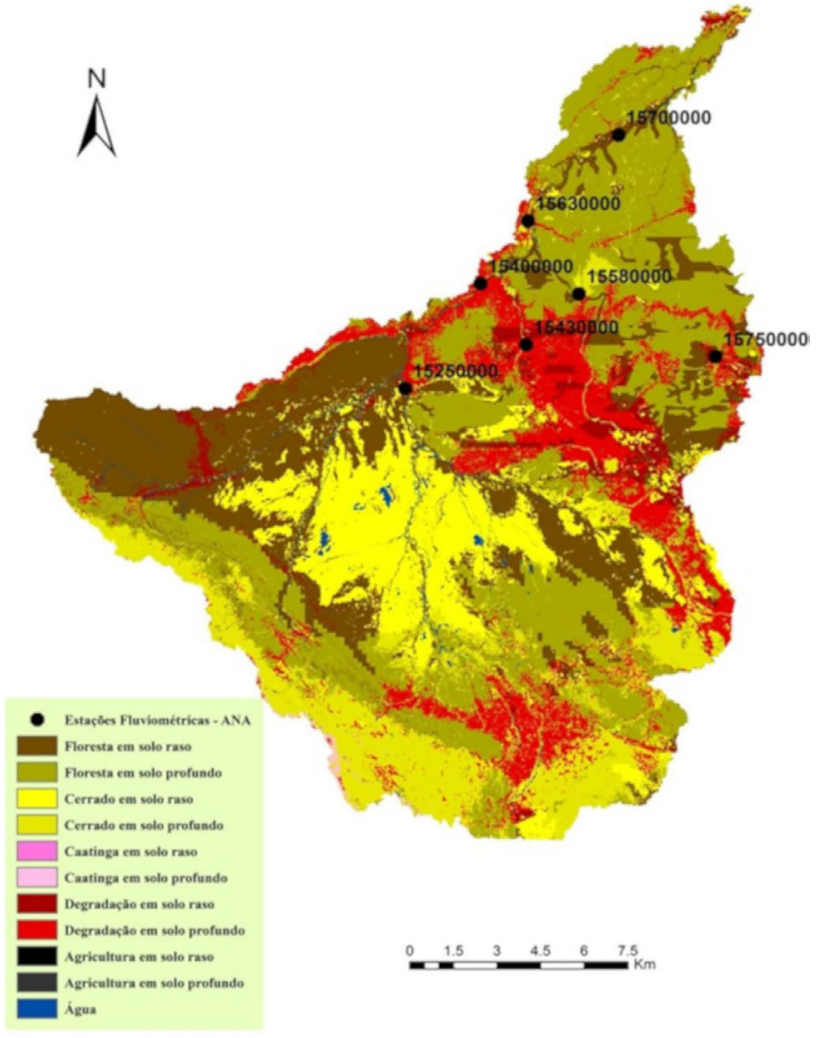

Figura 2 - Mapa das Unidades de Resposta Hidrológica - URH bacia do Rio Madeira no modelo MGB-IPH, juntamente com as estações fluviométricas selecionadas para a calibração e validação do modelo MGBIPH. Fonte: Vegetação - vegetação foi elaborado pelo Projeto ProVeg (Sestini et al., 2002), Solo - mapas de solos do RADAMBrasil (dentro do país), FAO e SOTERLAC (fora do país), reclassificados para geração das Unidades de Resposta Hidrológica - URH.

(OGCM) - Modelo Oceânico Modular versão 4p1 (MOM4p1) do Geophysical Fluid Dynamics Laboratory Climate via GFDLös Flexible Modular System (Griffies, 2009). As parametrizações físicas incluem o modelo de superfície Simplified Simple Biosphere Model - SSiB (Xue et al., 1991), o esquema de turbulência na camada limite planetária de Mellor-Yamada 2.0 (Mellor e Yamada, 1982), o esquema de convecção profunda de Grell e Devenyi (2002) e a parametrização de convecção rasa de Tiedke (1984). A dinâmica do modelo regional é desenvolvida na coordenada vertical Eta (Mesinger, 1984), útil para operar em regiões de orografia íngremes, como a Cordilheira dos Andes, na América do Sul. A precipitação é calculada pelo esquema de parametrização de cúmulos de Betts-Miller-Janjic (Janjic 1996) e pelo esquema de microfísica da nuvem Zhao (Zhao et al., 1997). Os esquemas de radiação de ondas curtas e longas são descritos por Lacis e Hansen (1974) e Fels e Schwarzkopf (1975), respectivamente. Os processos de superfície são representados pelo NOAH (Ek et al., 2003), que contém 4 camadas de solo para a temperatura e umidade, assim como 12 tipos de vegetação e 7 tipos de textura de solo. $\mathrm{O}$ mapa de vegetação foi elaborado pelo Projeto ProVeg (Sestini et al., 2002) com a inclusão dos dados do Projeto de Estimativa do Desflorestamento Bruto da Amazônia PRODES-DIGITAL (INPE, 2017) com as cenas de desflorestamento para o ano de 2015. Neste estudo o modelo foi configurado com resolução de $20 \mathrm{~km}$ na horizontal e 38 níveis na vertical.

O Modelo Hidrológico de Grandes Bacias do Instituto de Pesquisas Hidráulicas (Universidade Federal do Rio Grande do Sul - UFRGS) - MGB-IPH (Collischonn, 2001; Collischonn et al., 2007) é um modelo distribuído desenvolvido para aplicações em grandes bacias hidrográficas com limitação de dados $\left(10.000 \mathrm{~km}^{2}\right)$. O MGBIPH é um modelo baseado em processos que simula o ciclo hidrológico através de relações físicas e conceituais. São simuladas todas as etapas do ciclo hidrológico terrestre, incluindo balanço de água no solo, evapotranspiração, interceptação, escoamento total, subsuperficial e subterrâneo e escoamento na rede de drenagem. A versão do MGB-IPH neste estudo utiliza o modelo de propagação inercial ou hidrodinâmico descrito por Tucci (2005). O modelo inercial é fundamentado nas equações da continuidade e dinâmica de Saint Venant no qual permite simular rede de canais com confluências e defluências, vazão, nível do rio (cota) e extensão das áreas inundadas ao longo da bacia (Paiva et al., 2011,2013). No MGB-IPH a bacia é discretizada em minibacias e cada uma destas possui um trecho de rio correspondente. As minibacias são subdivididas em Unidades de Resposta Hidrológicas (Hydrological Response Units - HRU) que serão áreas de comportamento hidrológico similar, definidas pela combinação de tipos de solo e cobertura vegetal (Kouwen et al., 1993). A maioria dos parâmetros do modelo hidrológico é relacionada às características físicas da bacia, como topografia, cobertura vegetal e solo (Fig. 2), que são obtidas via imagens de satélites, mapas digitalizados e modelo digital de elevação MDE (Getirana et al., 2010). Os demais parâmetros são calibrados com algoritmo de otimização global multi-objetivo MOCOM-UA (Yapo et al., 1998).

Neste estudo foi realizado um único experimento numérico para o clima presente. $\mathrm{O}$ experimento consistiu em uma integração contínua de 46 anos referente ao período de 1960 a 2005, onde a concentração de dióxido de carbono (CO2) permaneceu constante em $330 \mathrm{ppm}$. As condições de fronteira provenientes do BESM-AO forçaram o modelo regional a cada 6 horas. A umidade e temperatura do solo iniciais, e a temperatura da superfície do mar (TSM) foram obtidas do BESM-AO 2.5, com a TSM atualizada diariamente no modelo regional Eta.

\subsection{Remoção de viés}

As simulações de precipitação provenientes do modelo Eta-BESM-OA foram utilizadas para forçar o modelo 
MGB-IPH no clima presente. Entretanto, devido aos erros sistemáticos presentes nos modelos climáticos realizou-se o processo de correção do viés conforme recomendado na literatura (Silva et al., 2006). Os métodos de correção dos erros sistemáticos mais empregados são baseados numa transformação da curva de distribuição de probabilidades de precipitação (Hay et al. (2002) e Wood et al. (2002)). No presente estudo, para correção dos erros sistemáticos do modelo regional Eta-BESM-OA se utilizou a função de distribuição de probabilidade normal tipo $t$ de Student (Spiegel, 1972) aplicada aos valores médios diários de precipitação observada e modelada. As métricas estatísticas utilizadas para avaliar o desempenho do modelo foram o viés (bias), a raiz quadrada do erro médio quadrático (RMSE) e a razão do desvio padrão (RDESV).

\subsection{Calibração do modelo hidrológico}

A fim de diminuir os erros entre os hidrogramas simulados e observados, na maioria dos estudos anteriores com o modelo MGB-IPH (Collischonn, 2006), optou-se por ajustar diferentes conjuntos de parâmetros para cada subbacia associada a um posto fluviométrico.

Assim, o modelo MGB-IPH possui uma série de parâmetros fixos e calibráveis que são definidos em diferentes etapas de sua aplicação. Os parâmetros fixos (Índice de Área foliar, Albedo, Resistência Superficial e Altura do Dossel) são utilizados no cálculo da evapotranspiração pelo método de Penmam - Monteith, estando assim associados com a vegetação existente em cada Unidade de Resposta Hidrológica (URH). Os parâmetros calibráveis (Capacidade de Armazenamento do Solo, Forma de relação entre armazenamento e saturação, Vazão durante a estiagem, Armazenamento residual, Vazão de base, entre outros) estão associados às propriedades físicas das URHs, e são aqueles para os quais o modelo é mais sensível. Tais parâmetros podem ser alterados no processo de calibração validando assim o uso do modelo para a bacia hidrográfica do rio Madeira.

É importante ressaltar que a existência de diversas incertezas nos resultados calculados pelo modelo, devidas a erros nos dados medidos, na estrutura do modelo e nos parâmetros obtidos por calibração, faz com que os valores dos parâmetros calibráveis não seja único e sim uma faixa de valores e diferentes combinações que geram resultados semelhantes (Collischonn, 2001; Collischonn et al., 2004; Bravo, Collischonn e Tucci, 2009). Segundo Tucci et al. (2002), a escolha de um conjunto de parâmetros irá variar de acordo com o objetivo da aplicação do modelo, pois geralmente, não é possível a otimização de várias funções objetivos diferentes, e portanto, existe também uma incerteza neste processo.

A calibração no modelo MGB-IPH foi realizada de forma automática utilizando algoritmos genéticos que consideram múltiplos objetivos os coeficientes Nash-Sut- cliffe (ENS), Nash-Sutcliffe para os logaritmos das vazões (ENSlog) e o erro do volume ( $\Delta \mathrm{V}$ em \%) na determinação dos parâmetros (Yapo et al., 1998). Os parâmetros calibrados foram: capacidade de armazenamento do solo $(\mathrm{Wm})$, parâmetro $b$ (define a relação entre a umidade do solo e a proporção de área saturada), parâmetro do escoamento de base (KBAS), parâmetro do escoamento subsuperficial (KINT), parâmetro de retardo do reservatório linear simples (TK). Os demais parâmetros, tais como: índice de área foliar (IAF); altura média da vegetação (Z), e a resistência superficial (rs) foram obtidos a partir da literatura (Ribeiro Neto et al., 2008; Paiva et al., 2013). Para a calibração do modelo hidrológico MGB-IPH se utilizou dados diários de precipitação das reanálises do EraInterim no período de 1990 a 1994, devido aos dados de vazão ter uma série mais completa.

\section{Resultados e Discussão}

\subsection{Ramo atmosférico do balanço de água}

A avaliação do desempenho do modelo Eta-BESMOA na representação do ramo atmosférico dos componentes do balanço de água na bacia do rio Madeira foi realizada para o período de 1979 a 2005. Os componentes avaliados foram precipitação, evapotranspiração, convergência de umidade e escoamento total. A Fig. 3 apresenta a precipitação média simulada pelo modelo Eta-BESMOA e os dados de reanálise do ERA-Interim (ECWMF) para as estações úmida (DJF) e seca (JJA) referente ao período de 1979 a 2005. Também são apresentados o viés (bias) e a raiz do erro médio quadrático (RMSE) para avaliação do desempenho.

O modelo regional Eta-BESM-OA conseguiu representar a variação espacial de precipitação sobre maior parte da bacia durante a estação chuvosa. Os maiores valores simulados estão presentes a montante e na porção central da bacia. Os maiores valores são devidos à presença da Cordilheira dos Andes e também do posicionamento da Zona de Convergência do Atlântico Sul (ZCAS), um dos principais sistemas causadores de precipitação na Amazônia e especialmente sobre a bacia do rio Madeira. Em DJF, o modelo regional subestimou a precipitação (3$5 \mathrm{~mm} \mathrm{dia}^{-1}$ ) na maior parte da bacia, principalmente na foz do rio Madeira no encontro com o rio Amazonas, mas superestimou a jusante e sobre as regiões íngremes da bacia (montante). O modelo Eta-BESM-OA conseguiu representar melhor a variação da precipitação na estação seca. Em JJA, os maiores valores de precipitação ocorreram sobre os Andes e na porção norte da bacia. Apesar de apresentar um erro relativo menor em JJA, o modelo regional superestimou a precipitação $\left(1 \mathrm{~mm} \mathrm{dia}^{-1}\right)$ na porção central da bacia, mas subestimou na região dos Andes e na foz do rio Madeira. Os erros sistemáticos sobre os Andes, em ambas as estações, mostra que o modelo regio- 

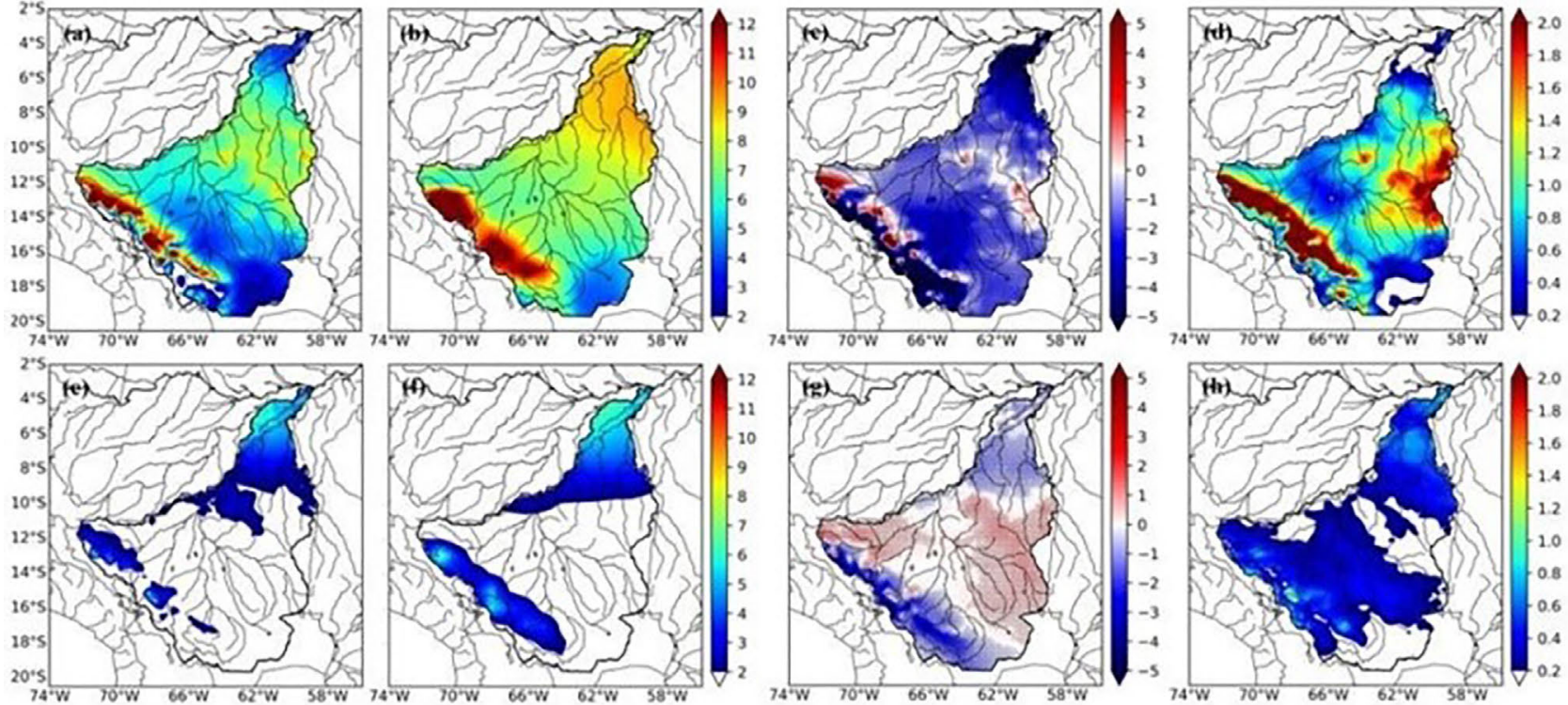

Figura 3 - Precipitação para o verão - DJF: (a) simulada pelo modelo Eta-BESM-OA, (b) reanálises do ERA-Interim, (c) Viés (mm dia ${ }^{-1}$ ), (d) RMSE (mm dia $^{-1}$ ); e inverno - JJA: (e) simulada pelo modelo Eta-BESM-OA, (f) reanálises do ERA-Interim, (g) Viés (mm dia ${ }^{-1}$ ), (h) RMSE (mm dia ${ }^{-1}$ ). As áreas onde as diferenças são significativas ao nível de confiança de $95 \%$ são marcadas por pontos pretos. Unidade: $\mathrm{mm}^{\text {dia }}{ }^{-1}$.

nal tem dificuldade em simular a precipitação em regiões íngremes.

A Fig. 4 apresenta a evapotranspiração média simulada pelo modelo Eta-BESM-OA e os dados das reanálises do Era-Interim (ECMWF) para estações de verão (DJF) e inverno (JJA). De forma geral, o modelo regional conseguiu representar a distribuição sazonal da evapotranspiração sobre a bacia do rio Madeira para o período úmido, com valores variando entre 3 e $4 \mathrm{~mm} \mathrm{dia}^{-1}$, estando próximos daqueles observado nas reanálises Era-Interim e por Marengo (2005) e Von Randow et al. (2004). Utilizando medidas de fluxo de calor latente em torres micrometeorológicas em área de floresta e pastagem em Rondônia (AM) durante o experimento de Grande Escala da Biosfera-Atmosfera na Amazônia - LBA (Gash et al., 2004), Von Randow et al. (2004) observaram medidas de
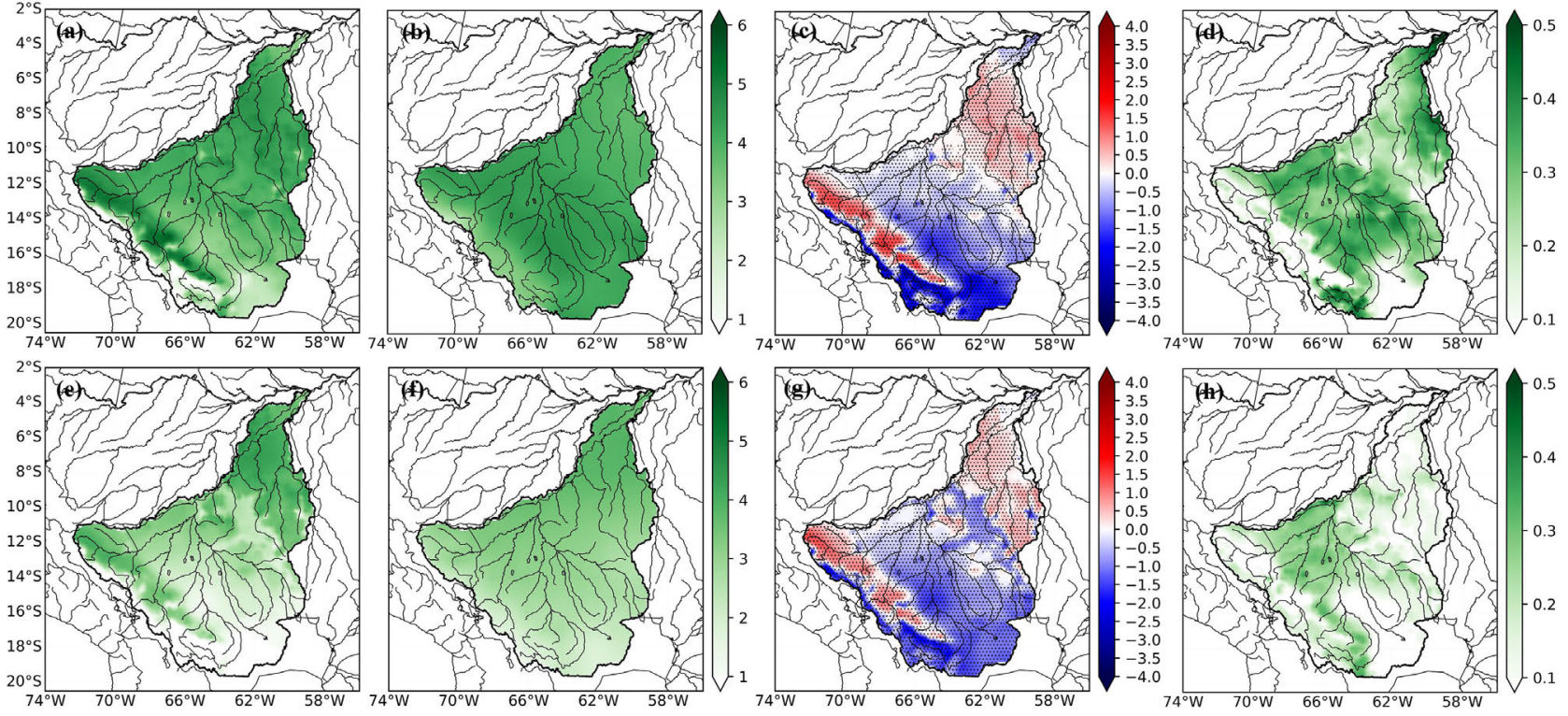

Figura 4 - Evapotranspiração para o verão - DJF: (a) simulada pelo modelo Eta-BESM-OA, (b) reanálises do ERA-Interim, (c) Viés (mm dia ${ }^{-1}$ ), (d) RMSE (mm.dia ${ }^{-1}$ ); e inverno - JJA: (e) simulada pelo modelo Eta-BESM-OA, (f) reanálises do ERA-Interim, (g) Viés (mm dia-1), (h) RMSE (mm dia ${ }^{-1}$ ). As áreas onde as diferenças são significativas ao nível de confiança de $95 \%$ são marcadas por pontos pretos. Unidade: mm dia $^{-1}$. 
evapotranspiração $\left(3.6 \mathrm{~mm} \mathrm{dia}^{-1}\right)$ similares aos encontrados no presente estudo, com valores um pouco maiores durante a estação seca. Em ambas as estações, os maiores valores simulados estão presentes nos Andes (montante) e a jusante da bacia. A variação sazonal da evapotranspiração simulada pelo modelo Eta-BESM-OA foi influenciada diretamente pela disponibilidade de energia (saldo de radiação) e umidade do solo nessa região. Entretanto, o modelo regional superestimou a evapotranspiração sobre os Andes $\left(3 \mathrm{~mm} \mathrm{dia}{ }^{-1}\right)$ e próximo à foz do rio Madeira $\left(1.5 \mathrm{~mm} \mathrm{dia}^{-1}\right)$ nas estações seca e úmida. Os menores (maiores) viés e RMSE foram observados durante o período seco (úmido) na bacia do rio Madeira.

A Fig. 5 apresenta a convergência de umidade média simulada pelo modelo Eta-BESM-OA e os dados de reanálise do ERA-Interim para os períodos úmido (DJF) e seco (JJA). De forma geral, o modelo Eta-BESM-OA conseguiu simular a variação sazonal e espacial da convergência de umidade durante o período úmido, apresentando valores positivos (convergência) na maior parte da bacia (3 a $6 \mathrm{~mm} \mathrm{dia}{ }^{-1}$ ). Esse período corresponde a maior atividade convectiva na região Amazônica. O modelo EtaBESM-OA subestimou a convergência de umidade na porção norte próximo a foz do rio Madeira ( 2 a $4 \mathrm{~mm} \cdot \mathrm{dia}^{-1}$ ) e superestimou na porção central e noroeste da bacia (montante). Durante o período seco, onde ocorre uma diminuição da atividade convectiva na região, a intensidade da convergência de umidade é reduzida sobre a bacia. Nesta estação, o modelo regional superestimou a convergência de umidade na maior parte da bacia ( 3 a $6 \mathrm{~mm}$ $\mathrm{dia}^{-1}$ ), exceto em algumas regiões isoladas nos Andes e próximo a foz do rio Madeira. A Fig. 6 apresenta o escoamento total médio (runoff) simulado pelo modelo EtaBESM-OA 2.5 e os dados de reanálise do ERA-Interim para o período úmido (DJF) e seco (JJA), respectivamente. A variação no escoamento total simulado pelo modelo regional foi determinada pela sazonalidade da precipitação sobre a bacia do rio Madeira, pois a evapotranspiração apresentou pequena variação durante o ano. Esse mesmo padrão também foi observado nas reanálises do ECMWF mostrando que o modelo Eta-BESM-OA consegue representar bem a sazonalidade no escoamento total sobre a bacia. A variação sazonal do escoamento é similar ao da precipitação. Na estação chuvosa, os valores do escoamento foram positivos (Precipitação - P > Evapotranspiração - E) em toda a bacia, e com valores mais intensos $\left(4 \mathrm{~mm} \mathrm{dia}{ }^{-1}\right)$ sobre os Andes e na porção central da bacia do rio Madeira. Na estação seca, os valores do escoamento de umidade foram negativos $(\mathrm{P}<\mathrm{E})$ na maior parte da bacia, com exceção da região dos Andes e a porção norte.
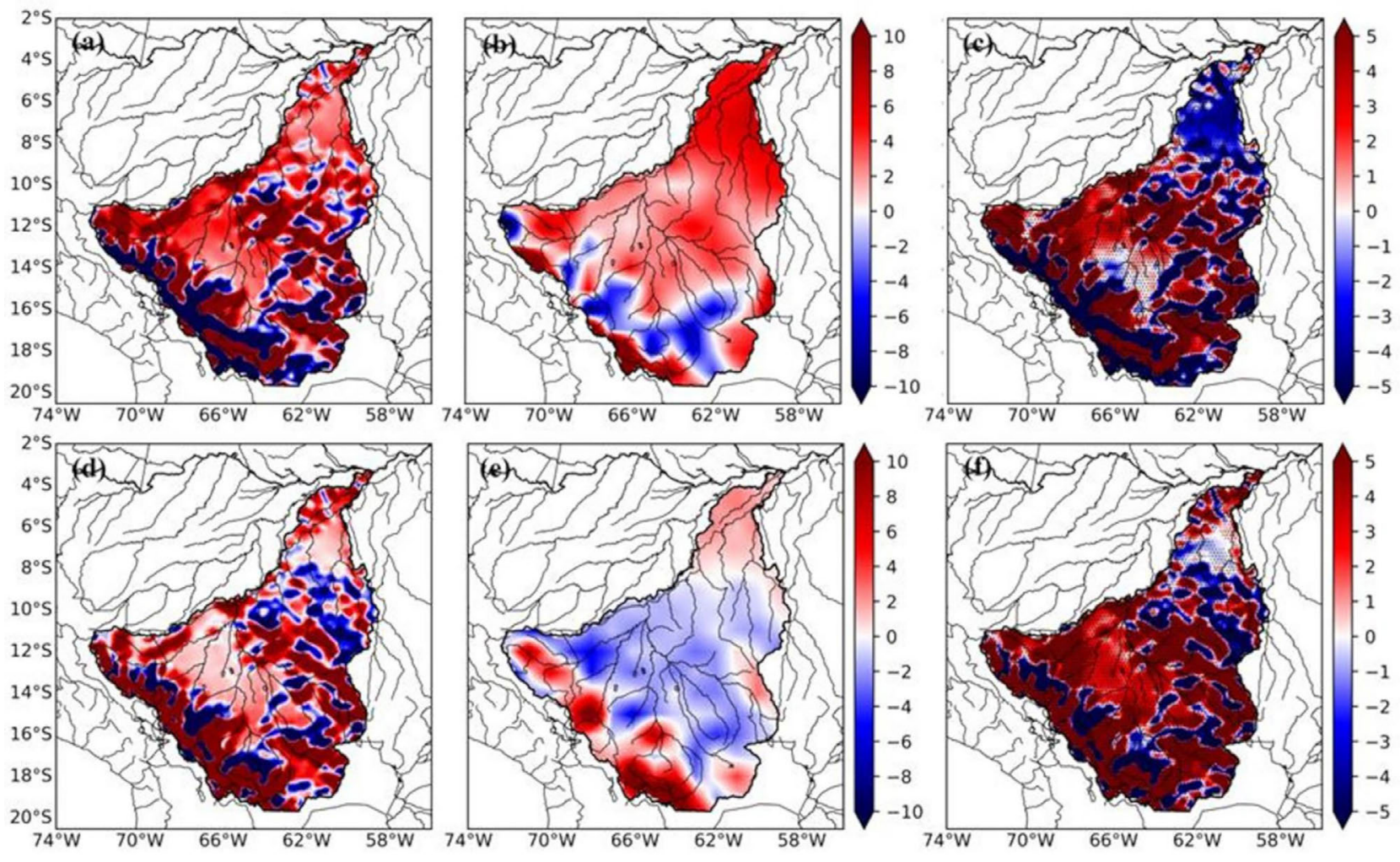

Figura 5 - Convergência de umidade para o verão - DJF: (a) simulada pelo modelo Eta-BESM-OA, (b) reanálises do ERA-Interim, (c) Viés (mm dia ${ }^{-1}$ ); e inverno - JJA: (d) simulada pelo modelo Eta-BESM-OA, (e) reanálises do ERA-Interim, (f) Viés (mm dia ${ }^{-1}$ ). As áreas onde as diferenças são significativas ao nível de confiança de $95 \%$ são marcadas por pontos pretos. Unidade: $\mathrm{mm} \mathrm{dia}^{-1}$. 

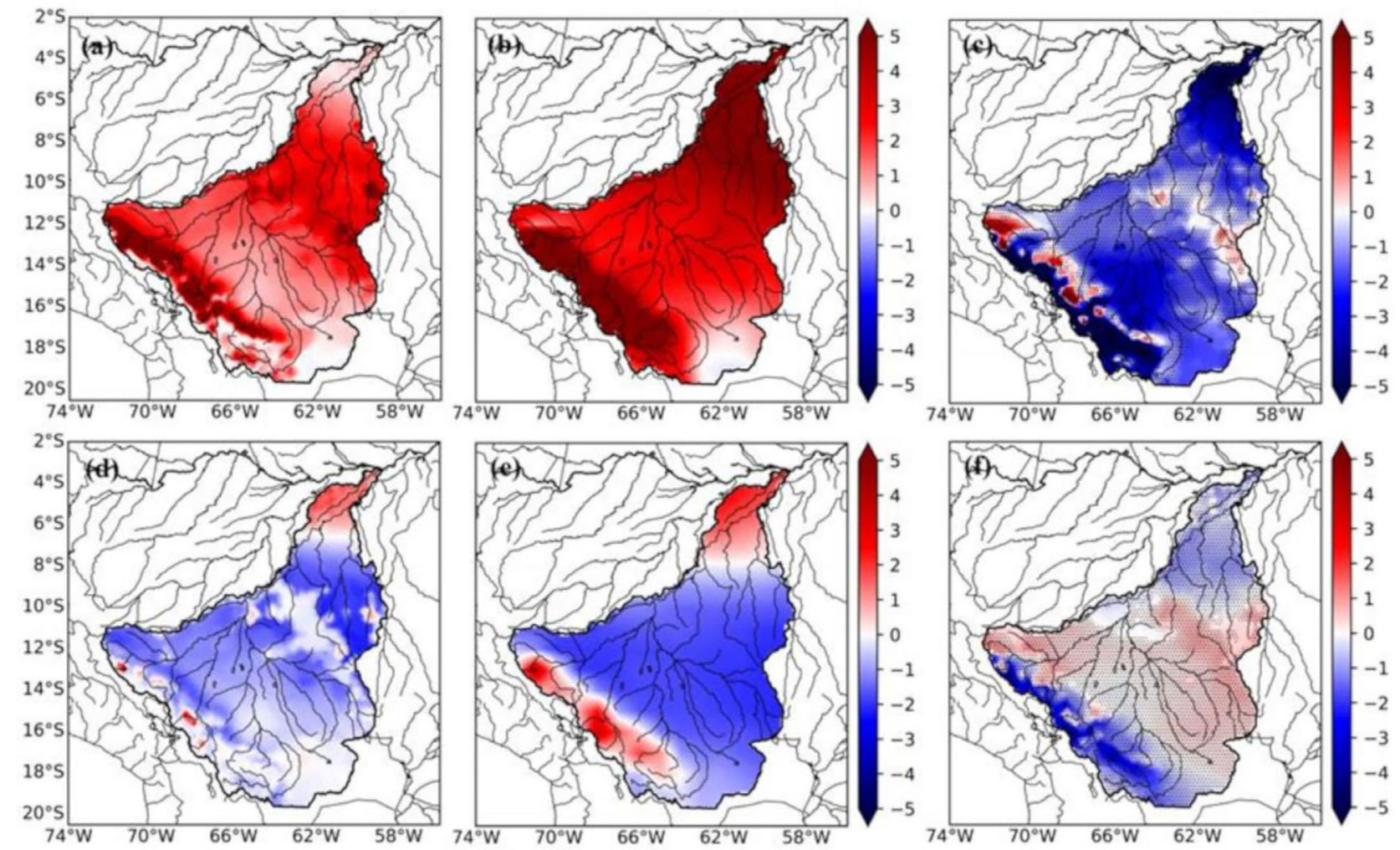

Figura 6 - Escoamento superficial para o verão - DJF: (a) simulada pelo modelo Eta-BESM-OA, (b) reanálises do ERA-Interim, (c) Viés (mm dia ${ }^{-1}$ ); e inverno - JJA: (d) simulada pelo modelo Eta-BESM-OA, (e) reanálises do ERA-Interim, (f) Viés (mm dia ${ }^{-1}$ ). As áreas onde as diferenças são significativas ao nível de confiança de $95 \%$ são marcadas por pontos pretos. Unidade: $\mathrm{mm} \mathrm{dia}^{-1}$.

De forma geral, o modelo regional subestimou o escoamento total na maior parte da bacia durante a estação úmida $\left(3 \mathrm{~mm}^{-1}\right.$ a $\left.5 \mathrm{~mm}^{-1}\right)$, mas na estação seca superestimou na porção central.

\subsection{Balanço de água}

A Tabela 2 apresenta os componentes do balanço de água na bacia do rio Madeira simulados pelo modelo EtaBESM-OA e pelas reanálises do Era-Interim (ECMWF) para a média anual, períodos úmido e seco. De forma geral, a bacia comportou-se como sumidouro de umidade atmosférica, no qual a precipitação (P) foi maior que a evapotranspiração (E) na média anual e estação úmida. De forma contraria, a bacia comportou-se como fonte de umidade $(\mathrm{P}<\mathrm{E})$ durante a estação seca apresentando valores menos intensos na convergência de umidade sobre a região. Esses resultados mostram que o modelo regional conseguiu capturar a característica de sumidouro de umidade sobre a bacia do Madeira. A precipitação média simulada pelo modelo regional nas estações úmida e seca foi de $6,0 \mathrm{~mm}$ $\mathrm{dia}^{-1}$ e 2,0 $\mathrm{mm} \mathrm{dia}^{-1}$, respectivamente. A convergência de umidade variou de $2,55 \mathrm{~mm} \operatorname{dia}^{-1}$ (convergência) a $-1,22 \mathrm{~mm} \mathrm{dia}^{-1}$ (divergência) entre o verão e inverno, mostrando um ciclo hidrológico mais intenso em relação às reanálises. De forma geral, apesar de conseguir simular as var- iações entre as estações seca e úmida, o modelo subestimou a precipitação (33\%), a evapotranspiração (12\%) e o escoamento total $(>100 \%)$, mas apresentou melhor desempenho na representação da convergência de umidade $(6 \%)$. A diferença entre a convergência de umidade e o escoamento superficial não foi semelhante para o modelo regional e as reanalises. As diferenças nos processos dinâmicos (vento) e de superfície representados por cada modelo podem explicar esse resultado. Comparando o balanço combinado atmosférico-hidrológico simulado pelo modelo regional na bacia do Madeira, a convergência de umidade $(\mathrm{C}=0,98 \mathrm{~mm}$ $\left.\mathrm{dia}^{-1}\right)$ não é balanceada pelo escoamento total $(\mathrm{R}=0,56 \mathrm{~mm}$ $\left.\mathrm{dia}^{-1}\right)$, com diferença média de $0.42 \mathrm{~mm} \mathrm{dia}^{-1}$. Este desequilíbrio (76\%) mostra um não fechamento do ciclo hidrológico na bacia do rio Madeira. Esse não fechamento pode estar associado à deficiência nas parametrizações de convecção e precipitação e a um período de integração insuficiente para que o modelo alcançasse o equilíbrio. Nas reanálises o desbalanço foi ordem de $25,3 \%$, mostrando um melhor fechamento no balanço de água em relação aquele simulado pelo modelo Eta-BESM-OA.

\subsubsection{Desempenho da remoção de viés}

Antes de forçar o modelo hidrológico MGB-IPH com a precipitação simulado pelo modelo climático rea- 
Tabela 2 - Componentes do balanço de água na bacia do Madeira simulados pelo modelo Eta-BESM-OA e os dados de reanálises do EraInterim (ECMWF) no período de 1979 a 2005 para média anual, estações úmida (wet) e seca (dry). Os componentes são: precipitação (P), evapotranspiração (E), escoamento superficial $(\mathrm{R})$ e convergência de umidade (C); P - E - C representando a medida absoluta do desbalanço; [(C / R ) 1] a medida relativa (\%) do desbalanço. Unidade: $\mathrm{mm} \mathrm{dia}^{-1}$

\begin{tabular}{lccc}
\hline Componentes $\left(\mathrm{mm} \mathrm{dia}^{-1}\right)$ & Era-Interim & Eta-BESM-OA & Erro (\%) \\
\hline \multicolumn{4}{c}{ Bacia do rio Madeira } \\
\hline P & 5.03 & 3.80 & -32.5 \\
R & 3.64 & 3.24 & -12.3 \\
C & 1.40 & 0.56 & -149.3 \\
P - E & 1.04 & 0.98 & -6.1 \\
P - E - C & 1.40 & 0.56 & \\
Desbalanço $=[(\mathrm{C} / \mathrm{R})-1](\%)$ & -25.3 & -0.42 & \\
\hline
\end{tabular}

\begin{tabular}{|c|c|c|c|}
\hline \multicolumn{4}{|c|}{ Úmido - DJF } \\
\hline $\mathrm{P}$ & 7.13 & 6.00 & -18.8 \\
\hline $\mathrm{E}$ & 4.10 & 3.80 & -7.9 \\
\hline $\mathrm{R}$ & 3.03 & 2.20 & -37.5 \\
\hline $\mathrm{C}$ & 1.60 & 2.55 & 37.3 \\
\hline$P-E$ & 3.03 & 2.20 & \\
\hline$P-E-C$ & 1.43 & -0.35 & \\
\hline Desbalanço $=[(\mathrm{C} / \mathrm{R})-1](\%)$ & -47.1 & 15.9 & \\
\hline \multicolumn{4}{|c|}{ Seco - JJA } \\
\hline$P$ & 2.38 & 2.00 & -18.8 \\
\hline $\mathrm{E}$ & 2.97 & 2.60 & -14.1 \\
\hline $\mathrm{R}$ & -0.59 & -0.60 & 1.4 \\
\hline $\mathrm{C}$ & 0.05 & -1.22 & 104.1 \\
\hline$P-E$ & -0.59 & -0.60 & \\
\hline$P-E-C$ & -0.64 & -1.78 & \\
\hline Desbalanço $=[(\mathrm{C} / \mathrm{R})-1](\%)$ & -108.5 & 103.0 & \\
\hline
\end{tabular}

lizou-se o processo de correção dos erros sistemáticos do modelo Eta-BESM-OA. A Fig. 7 mostra a variação sazonal da precipitação simulada pelo modelo regional Eta não corrigido (SC), corrigido (CC) e a reanálise do Era-Interim para a bacia do rio Madeira no período de 1995 a 2005. A Tabela 3 apresenta o desempenho do processo de correção do viés para média anual e os trimestres DJF e JJA. Observa-se um ganho de desempenho na representação do ciclo anual da precipitação no modelo regional Eta corrigido (CC). A redução dos erros durante a estação chuvosa é evidente na Fig. 7. Os parâmetros estatísticos apresentados na Tabela 3 mostram que os erros sistemáticos na precipitação são reduzidos com o procedimento de correção do viés adotado nesse estudo. Entretanto, para estação seca os valores do viés não mostraram melhorias na representação da precipitação.

\subsubsection{Vazões}

A Tabela 4 e a Fig. 8 apresentam o desempenho da climatologia das vazões simuladas com o modelo hidrológico MGB-IPH forçado com precipitação do modelo Eta-BESM-OA sem correção (SC) e com correção (CC), nas estações fluviométricas da bacia do rio Madeira. De forma geral, observou-se uma melhor representação do ciclo anual das vazões com a correção da precipitação no modelo regional. $\mathrm{O}$ efeito da correção teve papel mais importante durante o período de cheias em todas as estações fluviométricas. As estações que apresentaram melhor desempenho com a correção do viés foram Guajará-Mirim, Porto Velho e Manicoré com coeficiente Nash-Sutcliffe (ENS) da ordem de $0.88,0.90$ e 0.86 , respectivamente. As estações de Tabajara e Humbold tiveram os piores desempenhos, pois apesar de melhorar o ENS, apresentaram aumento no erro do volume total na correção da precipitação (Tabela 4). O modelo MGB-IPH não representou corretamente o instante dos máximos e mínimos da vazão na estação de Tabajara, apresentando um atraso da ordem de 3 meses na onda da cheia (Fig. 8d). Mesmo com a correção do viés, o modelo MGP-IPH tende a superestimar as vazões durante no período úmido nas estações de Guajará-Mirim, Ariquemes e Humboldt. Nas estações de Porto Velho, Humaitá e Manicoré, o modelo hidrológico simulou bem os máximos das enchentes (Fevereiro-Abril), mas superestimou a vazão durante a vazante (Agosto-Outubro). Os valores máximos das vazões nas estações de Porto Velho, Humaitá e Manicoré foram $35.000 \mathrm{~m}^{3} \mathrm{~s}^{-1}, 40.000 \mathrm{~m}^{3} \mathrm{~s}^{-1}$ e $45.000 \mathrm{~m}^{3} \mathrm{~s}^{-}$ ${ }^{1}$, respectivamente, estando próximas das vazões observadas pela ANA. Na estação seca, o modelo hidrológico tende a superestimar a vazão, com exceção da estação de Humboldt, onde a vazões simuladas estão próximas dos valores medidos pela ANA (Fig. 8g). A superestimativa dos máximos da vazão nas estações de Ariquemes e Humboldt deve-se, provavelmente, por estarem localizadas em região de floresta com solo raso, relevo acidentado, com variabilidade de alta frequência

Tabela 3 - Índices estatísticos para correção do viés da precipitação do modelo regional Eta-BESM-OA para a bacia do Rio Madeira no período de dezembro-janeiro-fevereiro (DJF), junho-julho-agosto(JJA) e anual. Sem correção (SC) e com correção (CC). Os parâmetros estatísticos são: Viés, RMSE e RDESV.

\begin{tabular}{lccc}
\hline Bacia do rio Madeira & DJF & JJA & Anual \\
\hline VIÉS-ETA-SC & -3.37 & 0.51 & -1.55 \\
VIÉS-ETA-CC & -0.35 & 0.53 & -0.26 \\
RMSE-ETA-SC & 3.89 & 0.96 & 2.03 \\
RMSE-ETA-CC & 0.75 & 0.74 & 0.66 \\
RDESV-ETA-SC & 0.80 & 0.64 & 0.79 \\
RDESV-ETA-CC & 0.94 & 0.78 & 0.94 \\
\hline
\end{tabular}




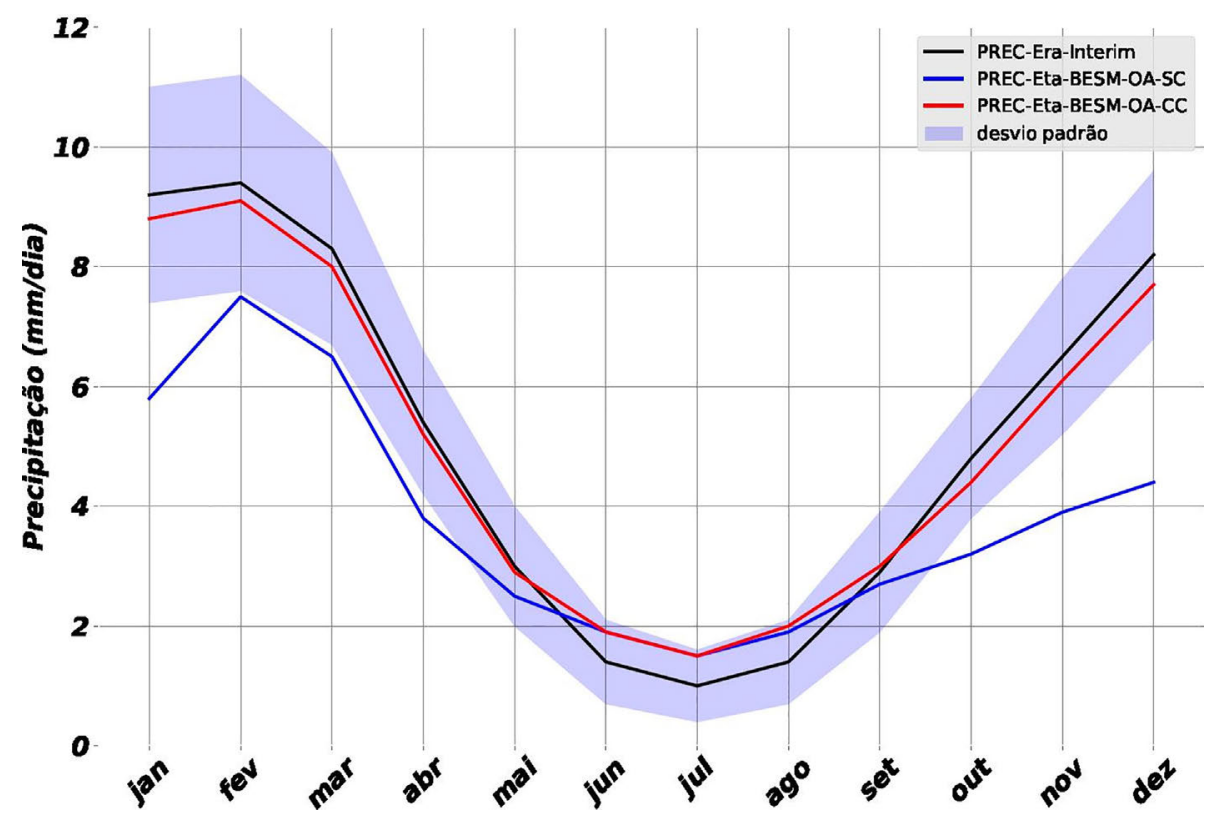

Figura 7 - Variação sazonal da precipitação das reanálises do Era-Interim (linha preta), as simuladas pelo modelo Eta-BESM-AO (linha azul) sem correção (Eta-BESM-AO SC), com correção (linha vermelha) (Eta-BESM-OA SC) e o desvio padrão médio em azul para a bacia do rio Madeira. Unidade: $\mathrm{mm} \mathrm{dia}{ }^{-1}$.
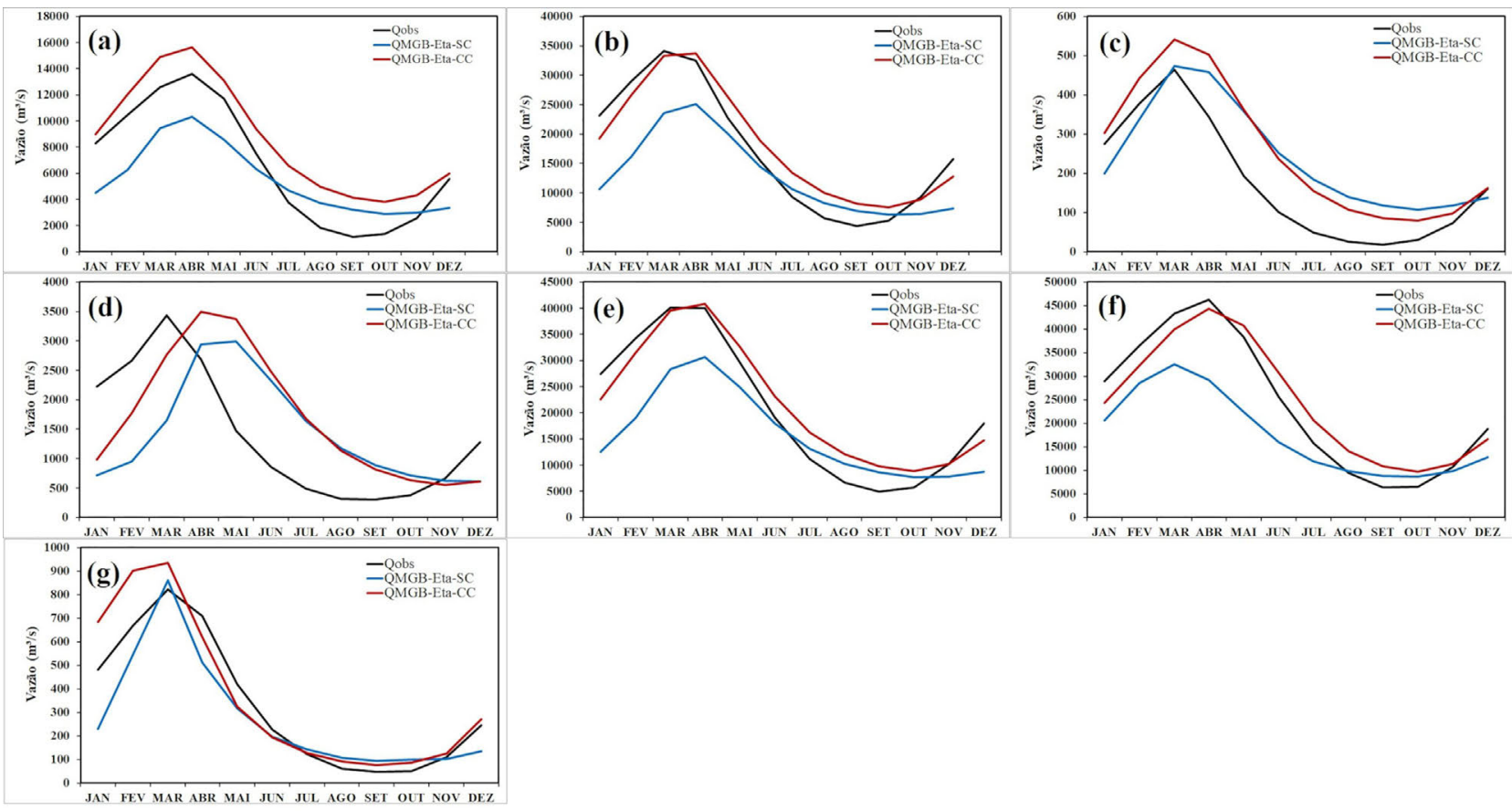

Figura 8 - Vazões sazonais provenientes da ANA (linha preta) e simulada pelo modelo MGB-IPH com precipitação do modelo Eta-BESM-OA sem correção (SC) (linha azul) e com correção (CC) (linha vermelha) para as estações fluviométricas da bacia rio Madeira: a) Guajará-Mirim (15250000), b) Porto Velho (15400000), c) Ariquemes (15430000), d) Tabajara (15580000), e) Humaitá (15630000), f) Manicoré (15700000) e g) Humboldt (15750000). Unidade: $\mathrm{m}^{3} \mathrm{~s}^{-1}$.

na vazão e erros nos dados de precipitação simulada. De forma geral, o modelo hidrológico MGB-IPH simulou bem as vazões nas estações de Guajará-Mirim, Porto Velho, Humaitá e Manicoré. Estas estações estão em regiões de extensa planície de inundação, predominância de solos profundos, hidrogramas mais suavizados, e principalmente, recebem contribuição de escoamentos subsuperficiais e subterrâneo. 
Tabela 4 - Desempenho das simulações das vazões obtidas a partir do modelo hidrológico MGB-IPH, forçado com os dados de precipitação do modelo Eta-BESM-OA sem a correção da precipitação (SC) e com a correção da precipitação (CC). Índices estatísticos: índice de eficiência de Nash e Sutcliffe (ENS), índice de eficiência de Nash e Sutcliffe entre logaritmo (ENSlog) e o erro no volume total $(\Delta \mathrm{V})$.

\begin{tabular}{|c|c|c|c|c|c|c|c|c|}
\hline \multirow[b]{2}{*}{$\mathrm{N}^{\circ}$} & \multirow[b]{2}{*}{ Código } & \multirow[b]{2}{*}{ Nome } & \multicolumn{3}{|c|}{ MGB-Eta-SC } & \multicolumn{3}{|c|}{ MGB-Eta-CC } \\
\hline & & & ENS & ENSlog & $\Delta \mathrm{V}$ & ENS & ENSlog & $\Delta \mathrm{V}$ \\
\hline 1 & 15250000 & Guajará-Mirim & 0.36 & 0.45 & -18.70 & 0.88 & 0.76 & 6.01 \\
\hline 2 & 15400000 & Porto Velho & 0.37 & 0.45 & -24.50 & 0.90 & 0.83 & 3.19 \\
\hline 3 & 15430000 & Ariquemes & 0.18 & 0.11 & 32.40 & 0.72 & 0.49 & 27.41 \\
\hline 4 & 15580000 & Tabajara & 0.23 & 0.27 & 2.44 & 0.68 & 0.60 & 20.81 \\
\hline 5 & 15630000 & Humaitá & 0.41 & 0.48 & -23.12 & 0.60 & 0.83 & 11.86 \\
\hline 6 & 15700000 & Manicoré & 0.36 & 0.47 & -26.01 & 0.86 & 0.75 & 6.00 \\
\hline 7 & 15750000 & Humboldt & 0.05 & 0.48 & -15.58 & 0.42 & 0.33 & 43.29 \\
\hline
\end{tabular}

\subsubsection{Nivel do rio}

Avaliou-se o desempenho do modelo MGB-IPH, com e sem correção da precipitação do Eta-BESM-OA, na representação do nível do rio nas estações de Porto Velho e Guajará Mirim. Como os dados de nível não são referenciados ao nível médio do mar, os dados observados e simulados foram padronizados seguindo método proposto por Paiva et al. (2013). Os erros foram avaliados através de cotagramas (Figs. 9a,b) e dos seguintes parâmetros estatístico: coeficiente de correlação, índice de eficiência de Nash Sutcliffe (ENS), erro absoluto de amplitude (Viés) A1 (m) e erro relativo da amplitude A2 (Viés \%), conforme mostrado na Tabela 5. As cotas simuladas pelo modelo MGB-IPH, com dados de precipitação corrigidos e não corrigidos do modelo Eta-BESM-OA, estão próximas das cotas observadas nas estações de Guajará-Mirim e Porto Velho. Entretanto, com a precipitação corrigida o desempenho do modelo hidrológico foi visivelmente melhorado, tanto nos cotagramas como nos parâmetros estatísticos. Na estação de Guajará-Mirim o modelo conseguiu corrigir os erros durante as cotas máximas, mas não simulou corretamente as cotas mínimas. Na estação de Porto Velho, o modelo hidrológico simulou corretamente o ciclo anual da cota, corrigindo os erros no período de recessão. O modelo hidrológico foi capaz de representar a translação das ondas de cheia e sua amplitude durante o período (Fig. 9). Apesar do aumento no ENS em ambas as estações com a correção da precipitação, a estação de Porto Velho apresentou melhor desempenho. Nesta estação, o coeficiente de correção aumentou para 0.90 e os vieses (bias) absolutos e relativos reduziram para 0.002 e 6.70 , respec- tivamente. Apesar do ganho no desempenho, os erros encontrados em Porto Velho podem ser explicados pelos erros na estimativa da largura da seção transversal do rio e também devido ao efeito de remanso do rio Amazonas, especialmente no posto de Porto Velho.

\subsection{4. Áreas de inundação}

Apresenta-se neste item, o desempenho do modelo hidrológico na representação da área de inundação, forçado com a precipitação proveniente das reanálises do Era-Interim e do modelo Eta-BESM-OA (com e sem correção). A avaliação foi realizada tomando por base a área de inundação simulada com precipitação das reanálises para toda a bacia do rio Madeira. Para esta avaliação, calculou-se a variação sazonal da área de inundação para período de 1995 a 2005 e também dois estudos de caso para dias de máximo e mínimo de inundação em um ano hidrológico típico (sem há ocorrência de eventos extremos) (Ano 1999). A variação sazonal da área de inundação é apresentada na Fig. 10. No período de março a maio (outubro-novembro) se observa à máxima (mínima) extensão da área de inundação utilizando dados de reanálises, com uma área média de aproximadamente $20.000 \mathrm{~km}^{2}(13 \%$ das áreas inundáveis) $\left(5.000 \mathrm{~km}^{2}-3 \%\right.$ das áreas inundáveis). $\mathrm{O}$ instante de máxima extensão da inundação apresenta um atraso da ordem de 3 meses em relação ao da precipitação (Ver Fig. 7). Isso também foi observado no máximo das vazões em algumas estações fluviométricas no rio Madeira (Fig. 8). As áreas de inundação com dados de precipitação do modelo Eta-BESM-AO, com e sem correção, conseguiram representar as características do

Tabela 5 - Estatística de avaliação dos erros entre níveis d'água padronizados dos simulados pelo modelo MGB-IPH com a precipitação do modelo regional EtaBESM-AO - sem correção-SC e com correção-CC e observados (CPRM).

\begin{tabular}{|c|c|c|c|c|c|c|c|c|c|c|}
\hline \multirow[b]{2}{*}{ Código } & \multirow[b]{2}{*}{ Rio } & \multicolumn{4}{|c|}{ Eta-SC } & \multicolumn{4}{|c|}{ Eta-CC } & \multirow[b]{2}{*}{$\mathrm{A}_{\mathrm{obs}}$} \\
\hline & & $\mathrm{R}$ & ENS & A $1(\mathrm{~m})$ & A $2(\%)$ & $\mathrm{R}$ & ENS & A $1(\mathrm{~m})$ & A $2(\%)$ & \\
\hline 15250000 & Mamoré & 0.84 & 0.38 & 0.250 & 500.0 & 0.83 & 0.62 & 1.010 & 2020.0 & 0.050 \\
\hline 15400000 & Madeira & 0.73 & 0.49 & -0.010 & -40.0 & 0.90 & 0.75 & 0.002 & 6.70 & 0.025 \\
\hline
\end{tabular}



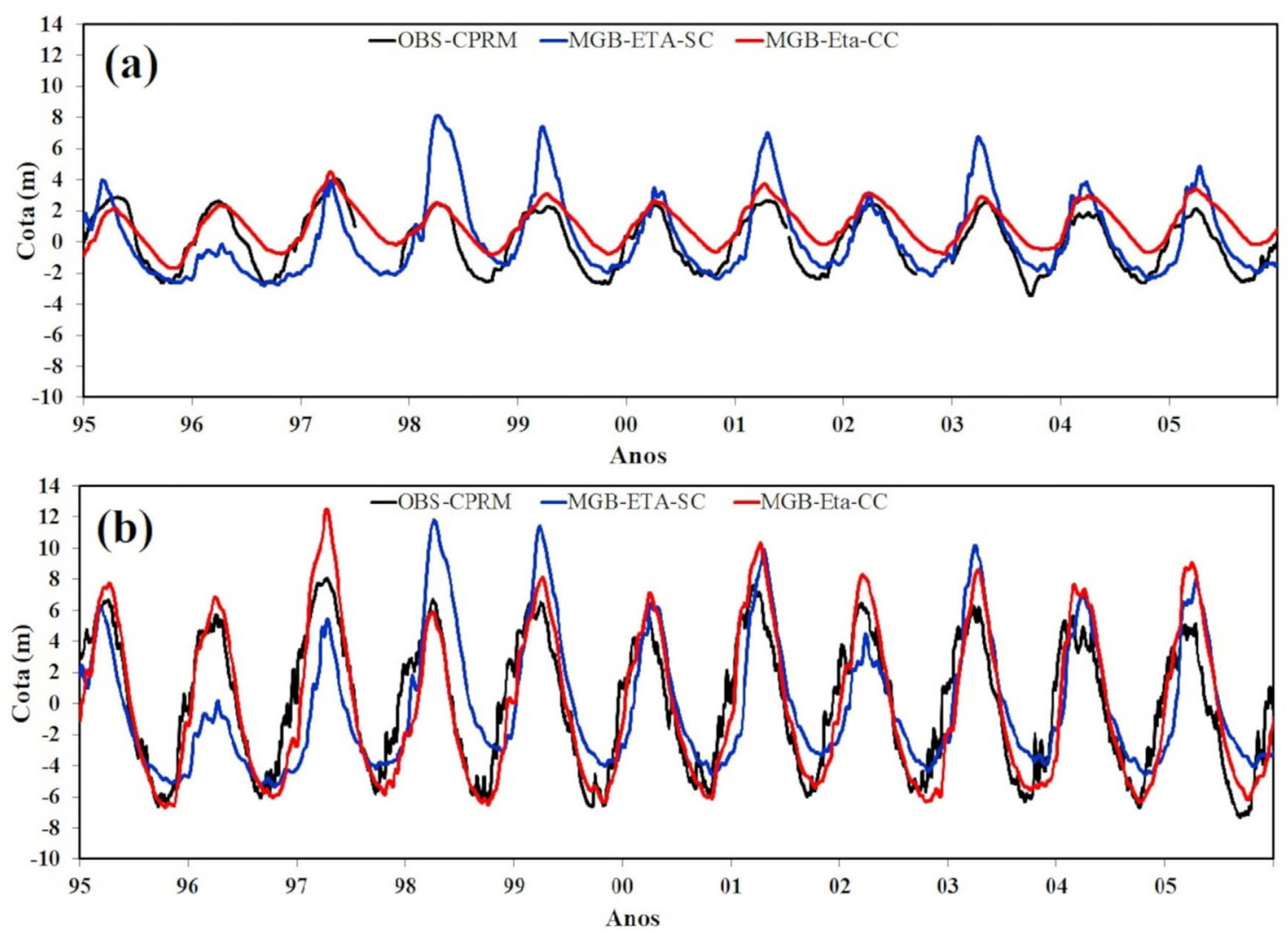

Figura 9 - Níveis (cotas) do rio observados (linha preta) e simulados pelo modelo MGB-IPH com os dados de precipitação do modelo Eta-BESM-OA sem a correção da precipitação (SC) (linha azul) e com a correção da precipitação (CC) (linha vermelha) para as estações fluviométricas da bacia rio Madeira: a) Guajará-Mirim (15250000), b) Porto Velho (15400000). Unidades: metros. Os níveis do rio foi padronizado seguindo o método proposto por Paiva et al. (2013).

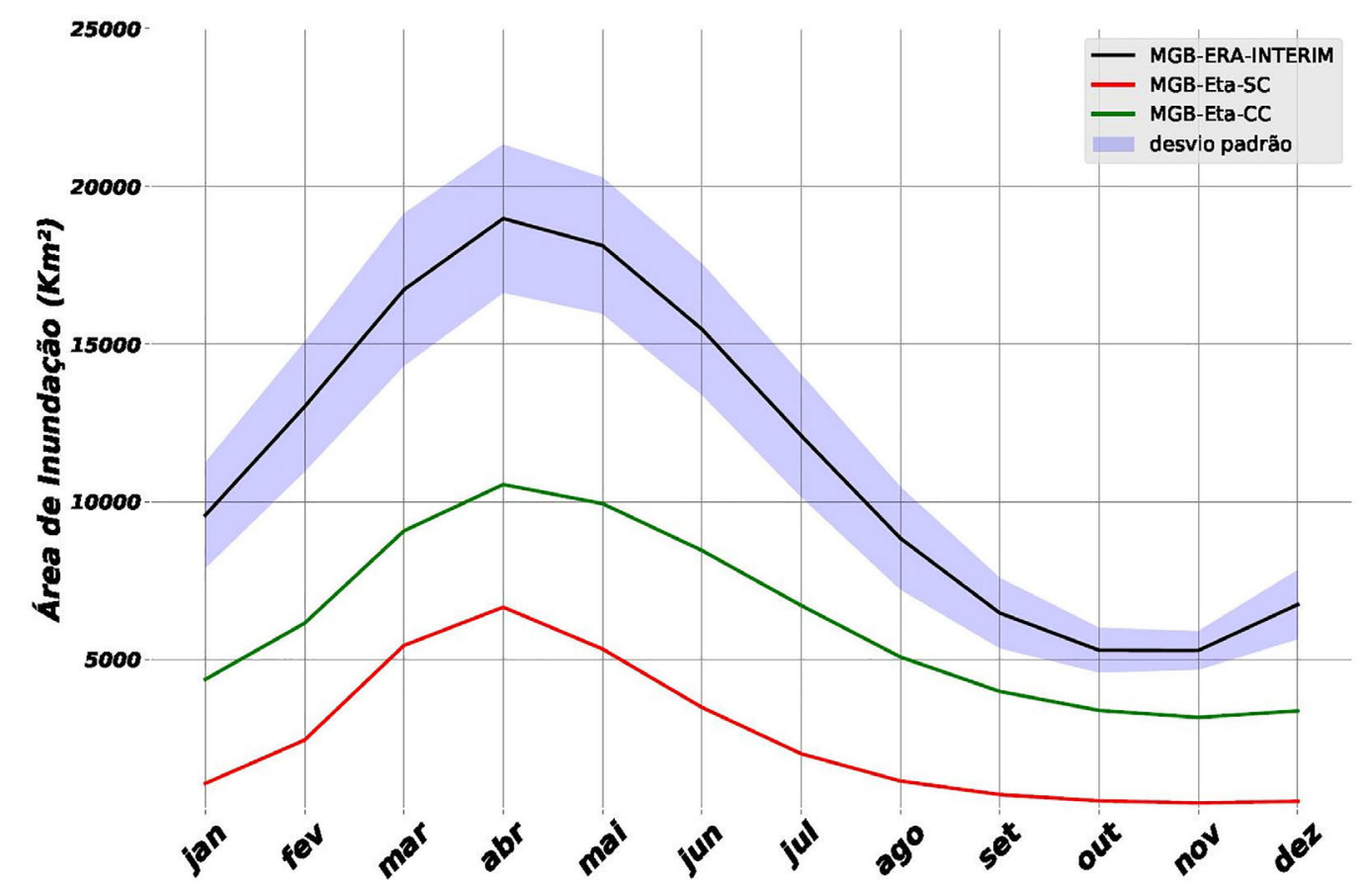

Figura 10 - Variação sazonal da área de inundação na bacia do rio Madeira simulada pelo modelo hidrológico MGB-IPH forçado com as precipitações do Era-Interim e do modelo regional Eta-BESM-OA sem correção (SC) e com correção (CC) e o desvio padrão médio em azul. Unidades: km² . 
ciclo anual, mas com valores inferiores em relação a inundação com dados de reanálises. Apesar da correção da precipitação do modelo Eta-BESM-OA, e a respectiva melhoria na simulação da área de inundação, o MGB-IPH ainda subestimou (20\%) a inundação, principalmente no período de cheia.

A Fig. 11 apresenta as áreas de inundações simuladas para o dia 10 de abril de 1999 (episódio de cheia) e 06 de junho de 1999 (episódio de vazante) localizadas à jusante da bacia do rio Madeira, região que mais sofre com as inundações e o efeito de remanso do rio Amazonas. De forma geral, a área de inundação simulada pelo modelo MGB-IPH, com o Eta-BESM-OA corrigido, foi melhor representa. Com a correção da precipitação o modelo simulou uma área de inundação da ordem de $29.728 \mathrm{~km}^{2}$ (20\% das áreas inundáveis) no período da cheia. Isso corresponde a uma redução de $23 \%$ no erro relativo na área de inundação sobre a bacia. Na estiagem a redução do erro na área de inundação foi de $10 \%$. Esses resultados mostram que o desempenho do modelo hidrológico é satisfatório na simulação da dinâmica sazonal das áreas de inundação na bacia do rio Madeira e, também que, o modelo hidrológico é uma ferramenta útil para estudos de variabilidades e mudanças climáticas, assim como, dos efeitos antropogênicos nos processos hidrológicos na bacia Amazônica.

\section{Conclusão}

Nesse estudo avaliou-se o desempenho do modelo regional Eta e o Modelo Hidrológico de Grandes Bacias (MGB-IPH), forçado com o Brazilian Earth System Model Ocean-Atmosphere versão 2.5 (BESM-OA 2.5), na representação dos componentes do balanço de água
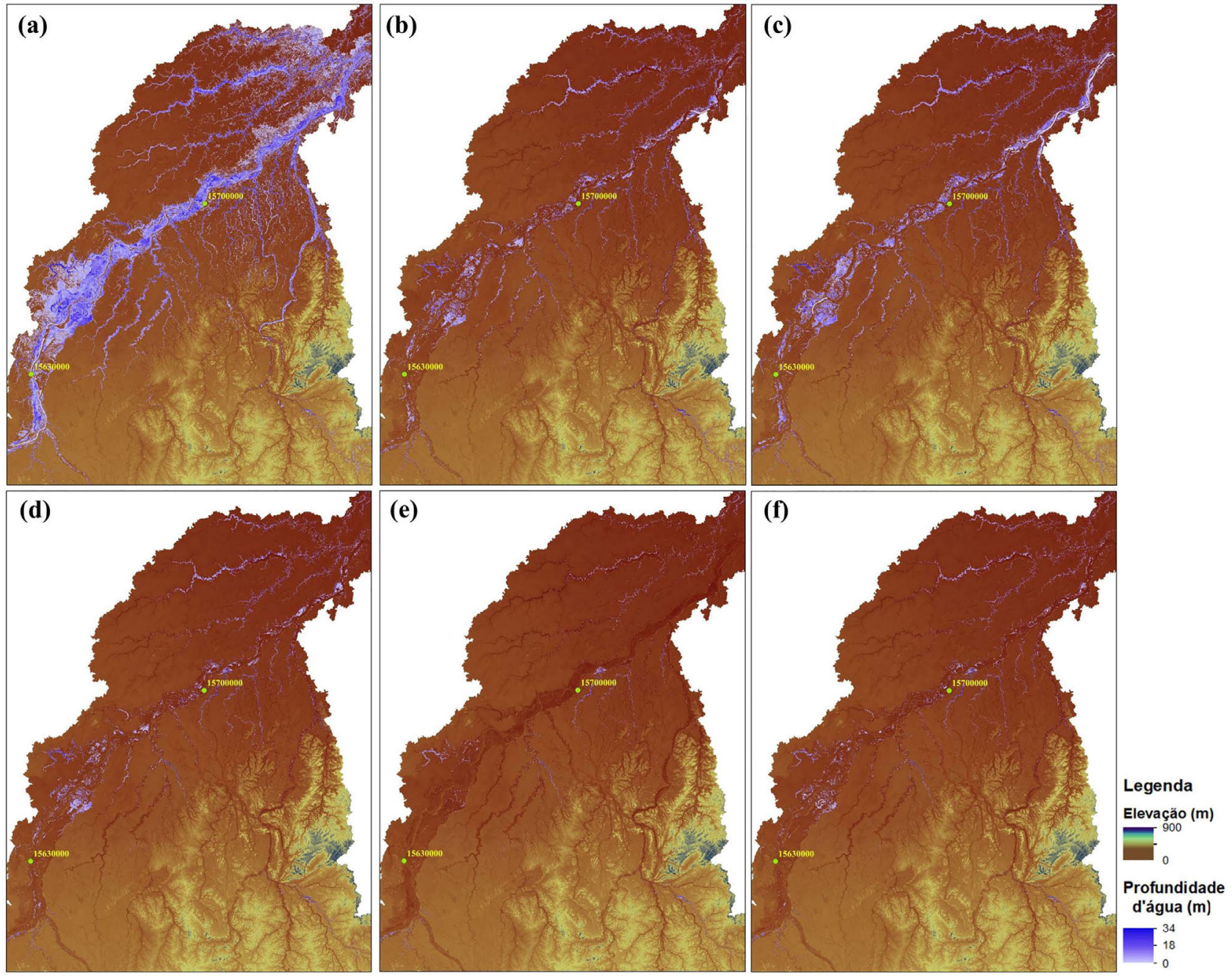

Figura - 11 - Área de inundação simulada pelo modelo MGB-IPH para a bacia do rio Madeira (Jusante) no dia 10/04/1999 (Cheia): a) MGB-IPH/EraInterim b) MGB-IPH/Eta-BESM-OA-SC; c) MGB-IPH/Eta-BESM-OA-CC e para o dia 06/11/1999 (Estiagem): d) MGB-IPH/Era-Interim e) MGB-IPH/ Eta-BESM-AO-SC; f) MGB-IPH/Eta-BEMS-AO-CC. Apresentam-se os valores de profundidade da água na planície de inundação em tons de azul e o Modelo Digital de Elevação em tons de vermelho. Unidade: metros. 
na bacia do rio Madeira para o período presente. De forma geral, o modelo regional Eta-BESM-OA e o MGB-IPH conseguiram representar os ramos atmosférico e terrestre dos componentes do balanço de água sobre a bacia do rio Madeira. Entretanto, nas regiões íngremes no oeste da bacia o modelo regional superestimou a intensidade da precipitação. A característica de sumidouro de umidade $(\mathrm{P}>\mathrm{E})$ sobre a bacia do rio Madeira foi simulada pelo modelo regional. Apesar de conseguir simular a variação sazonal dos componentes, o modelo subestimou a precipitação (33\%), a evapotranspiração $(12 \%)$ e o escoamento total $(>100 \%)$, mas apresentou melhor desempenho na representação da convergência de umidade (6\%). A diferença nos valores de convergência de umidade e escoamento total mostrou um não fechamento do balanço de água $(76 \%)$ na simulação sobre a bacia. Isso pode estar associado à deficiência nas parametrizações de convecção e precipitação no modelo regional. No ramo terrestre, o modelo hidrológico MGB-IPH, forçado com o modelo Eta-BESM-AO, conseguiu representar o ciclo anual das vazões, níveis do rio (cota) e área de inundação. A correção do erro sistemático no modelo regional melhorou o desempenho do modelo hidrológico nas estações de Guajará-Mirim, Porto Velho e Manicoré, mas em Tabajara e Humbold os resultados não foram satisfatórios. $\mathrm{O}$ modelo hidrológico conseguiu reproduzir a translação das ondas de cheia e sua amplitude durante o período. Um atraso observado da ordem de 3 meses entre os máximos da área de inundação e a precipitação também foi simulado corretamente pelo modelo MGB-IPH. O desempenho do modelo na simulação da área de inundação se mostra satisfatório no período de cheia com um erro relativo $20 \%$. Entretanto, na vazante os erros foram mais significativos. Isso não invalida a utilidade dos resultados do modelo já que o interesse na demanda dos recursos hídricos é durante as cheias. As estações com melhor desempenho estão em regiões de extensa planície de inundação e solos profundos onde o modelo hidrodinâmico do MGB-IPH é capaz de representar melhor os processos hidrológicos de armazenamento em planície de inundação e efeitos de remanso. O desempenho do modelo hidrológico se mostrou satisfatório na simulação da dinâmica sazonal dos processos hidrológicos e balanço de água na bacia do rio Madeira, indicando que o MGB-IPH é uma ferramenta útil para estudos de variabilidade climática, mudanças no clima e no uso da terra, e também para sistemas operacionais de previsão hidrológica na bacia Amazônica. Nesse estudo utilizou-se apenas uma única integração numérica climática, desta forma, recomenda-se para estudos futuros a utilização de vários membros nas integrações, uma vez que, simulações utilizando técnica de ensemble (conjunto) demonstram apresentar melhor desempenho.

\section{Agradecimentos}

Este artigo é parte da Dissertação de Mestrado do Programa de Pós-Graduação em Clima e Ambiente (CLIAMB) da Universidade do Estado do Amazonas (UEA) / Instituto Nacional de Pesquisas da Amazônia (INPA). Os autores agradecem a Agencia Nacional de Águas (ANA), ao Serviço Geológico do Brasil (CPRM), ao Ministério da Ciência, Tecnologia, Inovações e Comunicações (MCTI) por financiamento adicional, ao Centro de Previsão de Tempo e Estudos Climáticos - Instituto Nacional de Pesquisas Espaciais (CPTEC/INPE) por disponibilizar o Supercomputador TUPÃ para realização das integrações numéricas, o Laboratório de Modelagem do Sistema Climático Terrestre (LABCLIM) da Universidade do Estado do Amazonas (UEA) por disponibilizar a estrutura física e computacional - Cluster Tambaqui. O primeiro autor agradece a Coordenação de Aperfeiçoamento de Pessoal de Nível Superior - CAPES pela concessão da bolsa de estudo.

\section{Referências}

ANTAQ - Agencia Nacional de Transportes Aquaviários. Relatório Anual do Transporte de Cargas na Hidrovia do Rio Madeira. Brasília: Superintendência de Navegação Interior, 2011.

BRAVO, J.M.; COLLISCHONN, W.E TUCCI, C.E.M. Verificação da Eficiência e Eficácia de um Algoritmo Evolucionário Multi-Objetivo na Calibração Automática do Modelo Hidrológico IPH II. Revista Brasileira de Recursos Hídricos, v. 14, n. 3, p. 37-50. 2009.

CHAUDHARI, S.; POKHREL, Y.; MORAN, E.; MIGUEZMACHO, G. Multi-decadal hydrologic change and variability in the Amazon River basin: understanding terrestrial water storage variations and drought characteristics. Hydrology \& Earth System Sciences, v. 23, n. 7, p. 28412862, 2019.

CHOU, S.C.; MARENGO, J.A.; LYRA, A.A.; SUEIRO, G.; PESQUERO, J.F.; ALVES, L.M.; KAY, G.; BETTS, R.; CHAGAS, D.J.; GOMES, J.L.; BUSTAMANTE, J.F.; TAVARES, P. Downscaling of South America present climate driven by 4 -member HadCM3 runs. Climate dynamics, v. 38, n. 3-4, p. 635-653, 2012.

CHOU, S.C.; LYRA, A.; MOURÃO, C.; DERECZYNSKI, C.; PILOTTO, I.; GOMES, J.; BUSTAMANTE, J.; TAVARES, P.; SILVA, A.; RODRIGUES, D.; CAMPOS, D.; CHAGAS, D.; SUEIRO, G.; SIQUEIRA, G.; NOBRE, P.; MARENGO, J. Evaluation of the Eta simulations nested in three global climate models. American Journal of Climate Change, v. 3, n. 5, p. 438, 2014a.

CHOU, S.C.; LYRA, A..; MOURÃO, C.; DERECZYNSKI, C.; PILOTTO, I.; GOMES, J.; CAMPOS, D. Assessment of climate change over South America under RCP 4.5 and 8.5 
downscaling scenarios. American Journal of Climate Change, v. 3, n. 5, p. 512, 2014 b.

COLlischONN, W. Simulação HidrolóGica de Grandes Bacias. Tese de Doutorado em Engenharia de Recursos Hídricos e Saneamento Ambiental, Universidade Federal do Rio Grande do Sul, Porto Alegre. 270 p., 2001.

COLLISCHONN, W.; TUCCI, C.E.M.; FAILACHO GALLO, N. Avaliação do método de Muskingum Cunge não linear com conservação de volume para propagação de cheias em rios. In: Congresso Latinoamericano de Hidráulica, São Pedro, 2004.

COLLISCHONN, B. Uso De Precipitação Estimada Pelo Satélite TRMM Em Modelo Hidrológico Distribuído. Dissertação de Mestrado, UFRGS, Porto Alegre, 2006.

COLLISCHONN, B.; ALLASIA, D.; COLLISCHONN, W.; TUCCI, C. E. M. Desempenho do satélite TRMM na estimativa de precipitação sobre a bacia do Paraguai superior. Revista Brasileira de Cartografia, v. 59, n. 5, p. 878-895, 2007.

DALAGNOL, R.; BORMA, L.D.S.; MATEUS, P.; RODRIGUEZ, D.A. Assessment of climate change impacts on water resources of the Purus Basin in the southwestern Amazon. Acta Amazonica, v. 47, n. 3, p. 213-226, 2017.

DEE, D.P.; UPPALA, S. M.; SIMMONS, A.J.; BERRISFORD, P.; POLI, P.; KOBAYASHI, S.; BECHTOLD, P. The ERA-Interim reanalysis: Configuration and performance of the data assimilation system. Quarterly Journal of the Royal Meteorological Society, v. 137, n. 656, p. 553597, 2011.

DOUGHTY, C.E.; METCALFE, D.B.; GIRARDIN, C.A.J.; AMÉZQUITA, F.F.; CABRERA, D.G.; HUASCO, W.H.; FELDPAUSCH, T.R. Drought impact on forest carbon dynamics and fluxes in Amazonia. Nature, v. 519, n. 7541, p. 78-82, 2015.

EK, M.B.; MITCHELL, K.E.; LIN, Y.; ROGERS, E.; GRUMMEN, P.; KOREN, V.; GAYNO, G.; TARPLEY, J.D. Implementation of Noah land surface model advances in the National Centers for Environmental Prediction operational mesoscale Eta model. Journal of Geophysical Research: Atmospheres, v. 108, n. D22, 8851, 2003.

ESPINOZA VILLAR, J.C.; RONCHAIL, J.; GUYOT, J.L.; COCHONNEAU, G.; NAZIANO, F.; LAVADO, W.; VAUCHEL, P. Spatio-temporal rainfall variability in the Amazon basin countries (Brazil, Peru, Bolivia, Colombia, and Ecuador). International Journal of Climatology: A Journal of the Royal Meteorological Society, v. 29, n. 11, p. 1574-1594, 2009.

ESPINOZA, J.C.; RONCHAIL, J.; FRAPPART, F.; LAVADO, W.; SANTINI, W.; GUYOT, J.L. The major floods in the Amazonas River and tributaries (Western Amazon basin) during the 1970-2012 period: A focus on the 2012 flood. Journal of Hydrometeorology, v. 14, n. 3, p. 1000-1008, 2013.

ESPINOZA, J.C.; MARENGO, J. A.; RONCHAIL, J.; CARPIO, J. M.; FLORES, L.N.; GUYOT, J.L. 2014. The extreme 2014 flood in south-western Amazon basin: the role of tropical-subtropical South Atlantic SST gradient. Environmental Research Letters, v. 9, n. 12, p. 124007, 2014.
FAO - FOOD AND AGRICULTURE ORGANIZATION. Digital Soil Map Of The World And Derived Soil Properties. Rome: FAO, 2003.

FELS, STEPHEN B.; SCHWARZKOPF, M. Daniel. The simplified exchange approximation: A new method for radiative transfer calculations. Journal of the Atmospheric Sciences, v. 32, n. 7, p. 1475-1488, 1975.

FIGUEROA, S.N.; BONATTI, J. P.; KUBOTA, P.Y.; GRELL, G.A.; MORRISON, H.; BARROS, S.R.; SILVA, J. The Brazilian global atmospheric model (BAM): performance for tropical rainfall forecasting and sensitivity to convective scheme and horizontal resolution. Weather and Forecasting, v. 31, n. 5, p. 1547-1572, 2016.

GASH, J.H.C.; HUNTINGFORD, C.; MARENGO, J.A.; BETTS, R.A.; COX, P.M.; FISCH, G.; FU, R.; GANDU, A.W.; HARRIS, P.P.; MACHADO, L.A.T.; VON RANDOW, C.; SILVA DIAS, M.A.F. Amazonian climate: results and future research. Theoretical and Applied Climatology, v. 78, n. 1-3, p. 187-193, 2004.

GETIRANA, A.C.V.; BONNET, M.P.; ROTUNNO FILHO, O.C.; COLLISCHONN, W.; GUYOT, J.L.; SEYLER, F.; MANSUR, W.J. Hydrological modelling and water balance of the Negro River basin: evaluation based on in situ and spatial altimetry data. Hydrological Processes, v. 24, n. 22, p. 3219-3236, 2010.

GLOOR, M.R.J.W.; BRIENEN, R.J.; GALBRAITH, D.; FELDPAUSCH, T.R.; SCHÖNGART, J.; GUYOT, J.L.; PHILLIPS, O.L. Intensification of the Amazon hydrological cycle over the last two decades. Geophysical Research Letters, v. 40, n. 9, p. 1729-1733, 2013.

GODDARD, L.; MASON, S.J.; ZEBIAK, S.E.; ROPELEWSKI, C.F.; BASHER, R.; CANE, M.A. Current approaches to seasonal to interannual climate predictions. International Journal of Climatology: A Journal of the Royal Meteorological Society, v. 21, n. 9, p. 1111-1152, 2001.

GRELL, G.A.; DÉVÉNYI, D. A generalized approach to parameterizing convection combining ensemble and data assimilation techniques. Geophysical Research Letters, v. 29, n. 14, p. 38-1-38-4, 2002.

GRIFFIES, S.M.; SCHMIDT, M.; HERZFELD, M.I.K.E. Elements of Mom4p1, v. 6. Princeton: GFDL Ocean Group Tech. Rep, p. 377, 2009.

GUYOT, J.L. Hydrogéochimie Des Fleuves De l'Amazonie Bolivienne. Tese de Doutorado, Bordeaux, 1992.

HAY, L.E.; CLARK, M.P.; WILBY, R.L.; GUTOWSKI, W.J.; LEAVESLEY, G.H.; PAN, Z.; ARRITT, R.W.; TAKLE, E.S. Use of regional climate model output for hydrologic simulations. Journal of Hydrometeorology, v. 3, n. 5, p. 571-590, 2002.

INPE. Projeto PRODES: Monitoring the Brazilian Amazon Forest by Satellite: 2017. São José dos Campos: INPE, 2017, disponível em http://www.obt.inpe.br/prodes/index. php, acesso em jan 2018.

JANJIC, Z.I. The step-mountain eta coordinate model: Further developments of the convection, viscous sublayer, and turbulence closure schemes. Monthly Weather Review, v. 122, n. 5, p. 927-945, 1994.

JÚNIOR, J.S.; TOMASELLA, J.; RODRIGUEZ, D.A. Impacts of future climatic and land cover changes on the hydro- 
logical regime of the Madeira River basin. Climatic Change, v. 129, n. 1-2, p. 117-129, 2015.

KOUWEN, N.; SOULIS, E.D.; PIETRONIRO, A.; DONALD, J.; HARRINGTON, R.A. Grouped response units for distributed hydrologic modeling. Journal of Water Resources Planning and Management, v. 119, n. 3, p. 289-305, 1993.

LACIS, A.A.; HANSEN, J. A parameterization for the absorption of solar radiation in the earth's atmosphere. Journal of the Atmospheric Sciences, v. 31, n. 1, p. 118-133, 1974.

MARENGO, J.A. Characteristics and spatio-temporal variability of the Amazon River Basin water budget. Climate Dynamics, v. 24, n. 1, p. 11-22, 2005.

MARENGO, J.A.; ESPINOZA, J.C. Extreme seasonal droughts and floods in Amazonia: causes, trends and impacts. International Journal of Climatology, v. 36, n. 3, p. 10331050, 2016.

MARENGO, J.A.; SOUZA JR., C.M.; THONICKE, K.; BURTON, C.; HALLADAY, K.; BETTS, R.A.; ALVES, L.M.; SOARES, W.R. Changes in climate and land use over the Amazon region: current and future variability and trends. Frontiers in Earth Science, v. 6, p. 228, 2018.

MELLOR, G.L.; YAMADA, T. Development of a turbulence closure model for geophysical fluid problems. Reviews of Geophysics, v. 20, n. 4, p. 851-875, 1982.

MESINGER, F.A. A blocking technique for representation of mountains in atmospheric models. Rivista di Meteorologia Aeronautica, v. 44, n. 1-4, p. 195-202, 1984.

MOLINIER, M.; GUYOT, J.L.; DE OLIVEIRA, E.; GUIMARÃES, V. Les régimes hydrologiques de l'Amazone et de ses affluents. L'hydrologie tropicale: géoscience et outil pour le développement, 209-222. IAHS Publ, Paris, França, n. 238, p. 209-222, 1996.

MOLION, L.C.B. A Climatonomic Study Of The Energy And Moisture Fluxes Of The Amazonas Basin With Considerations Of Deforestation Effects. Doctoral Thesis, University of Wisconsin, 1975.

NASH, J.E.; SUTCLIFFE, J.V. River flow forecasting through conceptual models part I - A discussion of principles. Journal of Hydrology, v. 10, n. 3, p. 282-290, 1970.

NOBRE, P.; SIQUEIRA, L.S.; DE ALMEIDA, R.A.; MALAGUTTI, M.; GIAROLLA, E.; CASTELÃO, G.P.; BAPTISTA JR., M. Climate simulation and change in the Brazilian climate model. Journal of Climate, v. 26, n. 17, p. 6716-6732, 2013.

NOBRE, C.A.; SAMPAIO, G.; BORMA, L.S.; CASTILLARUBIO, J.C.; SILVA, J.S.; CARDOSO, M. The fate of the Amazon Forests: land-use and climate change risks and the need of a novel sustainable development paradigm. Proc. Natl. Acad. Sci. USA, v. 113, p. 10759-10768, 2016.

PAIVA, R.C.; COLLISCHONN, W.; TUCCI, C.E. Large scale hydrologic and hydrodynamic modeling using limited data and a GIS based approach. Journal of Hydrology, v. 406, n. 3-4, p. 170-181, 2011.

PAIVA, R.C.D.; BUARQUE, D.C.; COLLISCHONN, W.; BONNET, M.P., FRAPPART, F.; CALMANT, S.; BULHOES MENDES, C.A. Large-scale hydrologic and hydrodynamic modeling of the Amazon River basin.
Water Resources Research, v. 49, n. 3, p. 1226-1243, 2013.

RADAMBRASIL. Programa de Integração Nacional, Levantamento de Recursos Naturais. Brasília: Ministério das Minas e Energia, 1982.

RIBEIRO NETO, A. Simulação Hidrológica na Amazônia: Rio Madeira. Tese de Doutorado em Engenharia Civil, Universidade Federal do Rio de Janeiro, Rio de Janeiro, 195 p., 2006.

RIBEIRO NETO, A.; SILVA, R.C.V.; COLLISCHONN, W.; TUCCI, C.E. Simulação na bacia Amazônica com dados limitados: rio Madeira. Revista Brasileira de Recursos Hídricos, v. 13, n. 3, p. 47-58, 2008.

SESTINI, M.F.; ALVALÁ, R.C.S.; MELLO, E.M.K.; VALERIANO, D.M.; CHOU, S.C.; NOBRE, C.A.; PAIVA, J.A.C.; REIMER, E.S. Elaboração de Mapas de Vegetação para Utilização em Modelos Meteorológicos e Hidrológicos (INPE-8972-RPQ/730). São José dos Campos: Instituto Nacional de Pesquisas Espaciais, 74 p., 2002.

SILVA, B.C.; TUCCI, C.E.M.; COLLISCHONN, W. Previsão de vazão com modelos hidroclimáticos. Revista Brasileira de Recursos Hídricos, v. 11, n. 3, p. 15-29. 2006.

SPIEGEL, M.R. Estatística. São Paulo: McGraw-Hill, 580 p., 1972.

TIEDKE, M. The sensitivity of the time-mean large-scale flow to cumulus convection in the ECMWF model. In: Workshop on Convection in Large-Scale Numerical Models, European Centre for Medium-Range Weather Forecasts, p. 297$316,1984$.

TUCCI, C.E.M.; CLARKE，R.T.; DIAS，P.L.S.; COLLISCHONN, W. Previsão De Médio Prazo Da Afluência De Reservatórios Com Base Na Previsão Climática. Projeto BRA/00/29. Relatório Final. Porto Alegre: Universidade Federal do Rio Grande do Sul, 2002.

TUCCI, C.E. Gestão de Águas Pluviais Urbanas. Programa de Modernização do Setor Saneamento. Brasília: Ministério das Cidades, 2005.

VON RANDOW, C.; MANZI, A.O.; KRUIJT, B.; DE OLIVEIRA, P.J.; ZANCHI, F.B., SILVA, R.L.; CARDOSO, F.L. Comparative measurements and seasonal variations in energy and carbon exchange over forest and pasture in South West Amazonia. Theoretical and Applied Climatology, v. 78, n. 1-3, p. 5-26, 2004.

WOOD, A.; MAURER, E.P.; KUMAR, A.; LETTENMAIER, D.P. Long-range experimental hydrologic forecasting for the eastern United States. Journal of Geophysical Research: Atmospheres, v. 107, n. D20, p. ACL 6-1-ACL 6-15, 2002.

XUE, Y.; SELLERS, P.J.; KINTER, J.L.; SHUKLA, J. A simplified biosphere model for global climate studies. Journal of Climate, v. 4, n. 3, p. 345-364, 1991.

YAPO, P.O.; GUPTA, H.V.; SOROOSHIAN, S. Multi-objective global optimization for hydrologic models. Journal of hydrology, v. 204, n. 1-4, p. 83-97, 1998.

ZHAO, Q.; BLACK, T.L.; BALDWIN, M.E. Implementation of the cloud prediction scheme in the Eta Model at NCEP. Weather and Forecasting, v. 12, n. 3, p. 697-712, 1997. 


\section{Endereços de Internet}

ANA - AGÊNCIA NACIONAL DAS ÁGUAS (Brasil). Hidroweb: Sistema de Informações Hidrológicas. Disponível em: http://www.snirh.gov.br/hidroweb.

Sistema de Informações Hidrológicas, http://www.snirh.gov.br/ hidroweb.
INSTITUTO NACIONAL DE PESQUISAS ESPACIAIS INPE (2017). PRODES. Disponível em: http://www.obt.inpe.br/ $\mathrm{OBT} /$ assuntos/programas/amazonia/prodes.

License information: This is an open-access article distributed under the terms of the Creative Commons Attribution License (type CC-BY), which permits unrestricted use, distribution and reproduction in any medium, provided the original article is properly cited. 